Portland State University

PDXScholar

\title{
Building Social Sustainability from the Ground Up: The Contested Social Dimension of Sustainability in Neighborhood-Scale Urban Regeneration in Portland, Copenhagen, and Nagoya
}

Jacklyn Nicole Kohon

Portland State University

Follow this and additional works at: https://pdxscholar.library.pdx.edu/open_access_etds

Part of the Regional Sociology Commons, and the Urban Studies and Planning Commons Let us know how access to this document benefits you.

\section{Recommended Citation}

Kohon, Jacklyn Nicole, "Building Social Sustainability from the Ground Up: The Contested Social Dimension of Sustainability in Neighborhood-Scale Urban Regeneration in Portland, Copenhagen, and Nagoya" (2015). Dissertations and Theses. Paper 2330.

https://doi.org/10.15760/etd.2327

This Dissertation is brought to you for free and open access. It has been accepted for inclusion in Dissertations and Theses by an authorized administrator of PDXScholar. Please contact us if we can make this document more accessible: pdxscholar@pdx.edu. 
Building Social Sustainability from the Ground Up:

The Contested Social Dimension of Sustainability in Neighborhood-Scale Urban

Regeneration in Portland, Copenhagen, and Nagoya

by

Jacklyn Nicole Kohon

A dissertation submitted in partial fulfillment of the requirements for the degree of

Doctor of Philosophy

in

Urban Studies

Dissertation Committee:

Paula C. Carder, Chair

Veronica Dujon

Jennifer Allen

Thaddeus Miller

Portland State University

2015 
(C) 2015 Jacklyn Nicole Kohon 


\section{Abstract}

In response to growing social inequality, environmental crises, and economic instability, sustainability discourse has become the dominant "master signifier" for many fields, particularly the field of urban planning. However, in practice many sustainability methods overemphasize technological and economic growth-oriented solutions while underemphasizing the social dimension. The social dimension of sustainability remains a "concept in chaos," drawing little agreement on definitions, domains, and indicators for addressing the social challenges of urban life. In contrast, while the field of public health, with its emphasis on social justice principles, has made significant strides in framing and developing interventions to target the social determinants of health (SDH), this work has yet to be integrated into sustainability practice as a tool for framing the social dimension. Meanwhile, as municipalities move forward with these lopsided efforts at approaching sustainability practice, cities continue to experience gentrification, increasing homelessness, health disparities, and many other concerns related to social inequity, environmental injustice, and marginalization. This research involves multi-site, comparative case studies of neighborhood-scale sustainability planning projects in Portland, U.S.; Copenhagen, Denmark; and Nagoya, Japan to bring to light an understanding of how the social dimension is conceptualized and translated to practice in different contexts, as well as the challenges planners, citizen participants, and other stakeholders encounter in attempting to do so. These case studies find that these neighborhood-scale planning 
efforts are essentially framing the social dimension in terms of principles of SDH. Significant challenges encountered at the neighborhood-scale relate to political economic context and trade-offs between ideals of social sustainability, such as social inclusion and nurturing a sense of belonging when confronted with diverse neighborhood actors, such as sexually oriented businesses and recent immigrants. This research contributes to urban social sustainability literature and sustainability planning practice by interrogating these contested notions and beginning to create a pathway for integration of SDH principles into conceptualizations of social sustainability. 


\section{Acknowledgments}

This dissertation represents a journey fueled by the generosity of inspiring people. I am deeply appreciative of the participants of this study for inviting me into their communities, sharing their time, and conveying their perspectives.

Many, many thanks to my committee for providing crucial feedback, guidance, encouragement, and inspiration throughout this process. In particular, Paula Carder, to whom I owe a great debt, has been the most inspiring professor, advisor, chair, supervisor, mentor, and friend I could have ever imagined. Her encouragement, patience, generosity, trust, and good humor alone have made all of this possible. Veronica Dujon has been extremely caring, encouraging, and endlessly inspirational throughout this project. Jennifer Allen and Thad Miller were instrumental in challenging me to think outside of my disciplinary boundaries. I am very thankful to the faculty and staff at the Toulan School of Urban Studies and Planning and the School of Community Health at Portland State University. Special thanks to my exam committee members Charles Heying and Vivek Shandas - and to Ethan Seltzer for supporting my desire to connect with Japan in this project. Thanks to Rick Lockwood for that first research methods course all those years ago.

Special thanks to the many key people who connected, supported, transcribed, interpreted, translated, and in many other ways provided crucial support for this effort, including Akito Murayama, Patrick Driscoll, Aubrey Limburg, Mari Watanabe, Mako 
Ikeda, Liu Xue, Masami Nishishiba, Nathan Solbach, and Saumya Kini. I am thankful for camaraderie, guidance, and moral support from Arlie Adkins, Melissa Cannon, Dillon Mahmoudi, Jamie Jones, Jost Lottes, Iris Wernher, Emily Becker, Scotty Ellis, Moriah McSharry McGrath, Lauren Larin, Nicole Iroz-Elardo, Jenny Weinstein, the Hive of Innovation, and so many others. Thanks to the Urban Studies Writing Interest Group for workshopping earlier pieces from this work. Tremendous gratitude goes to the University Studies Program and my faculty mentors, Roslyn Farrington and Leanne Serbulo, who appeared just at the right time in my journey to inspire me beyond belief.

Thanks to my employers and contributors, including PSU's Institute on Aging, the University Studies Program, the Laurence R. Foster Memorial Scholar Program, the Terrie Fox Wetle Scholarship, the Institute for Sustainable Solutions, Nancy Chapman Endowed Scholarship, and the Marie Brown Travel Award. I am forever grateful to Portland State University for opening the door to this journey and becoming my second home.

Deep gratitude goes to my family -Mike, Debbie, Miho, Izumi, Jeramey, Josh, Stacy, Ayumi, Nobuaki, Jesse, Morgan, Simon, and Phoebe - and to my other family Monica, Whitney, Andy, John, Elliott, Bethany, Vanessa, Jenine, Josh, Carolyn, and many others for providing key support throughout the journey. My deepest gratitude goes to my love, Jun Suzuki, for being my most devoted cheerleader, for always being there, for always believing in me, and for celebrating each step of the way. This is all for you. 


\section{Table of Contents}

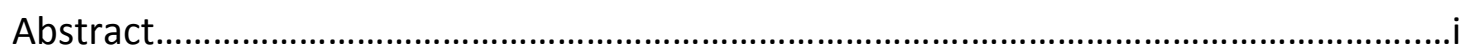

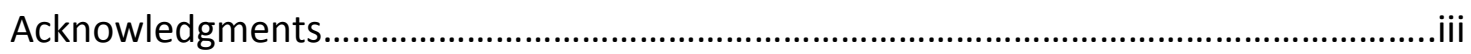

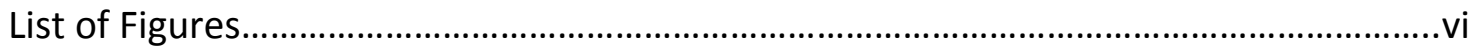

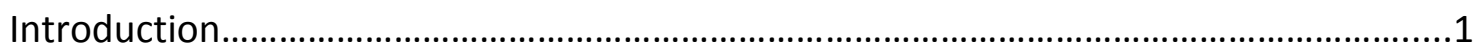

\section{Chapter One}

Interpretations of the Social Dimension of Sustainability in Urban Regeneration Practice:

Application of a Social Determinants of Health Lens......................................................

\section{Chapter Two}

"And then it goes political": The Contested Political Economy of Planning for Social

Sustainability in Urban Neighborhoods.

\section{Chapter Three}

Who Belongs in the Neighborhood? Negotiating Social Inclusion and a Sense of Belonging in Planning for Urban Social Sustainability

Conclusion

References

Appendix: Interview Results and SDH Template Analysis Summary .139 


\section{List of Figures}

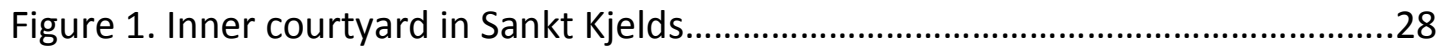

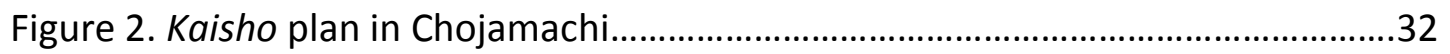




\section{Introduction}

Urban regions face many complex challenges related to growing inequality, environmental degradation, and economic distress. Though these challenges may seem disparate, their roots can be traced to a history of urban development based in a neoliberal capitalist system in an ever-globalizing world. This system has relied on mainly top down approaches to urban planning and has perpetuated vast imbalances in social, environmental, and economic systems in the urban landscape. These historical imbalances can be felt today in any major city in the U.S. and abroad in patterns of land use, social tensions, and damaged ecosystems.

Researchers and practitioners are grappling with how to repair the urban systems and urban problems that have resulted from the forces of globalization and unsustainable approaches to urban development. Urban regions function through an interconnected, interdependent web of dynamic systems, including transportation, socio-cultural networks, waste management, land use, and energy delivery, for example. Thus, many have realized that an approach to sustainable solutions requires an integrated, holistic perspective (Hallsmith, 2003; Zeemering, 2009; Campbell, 1996).

As a response to this shift in thinking, the discussion in practice on urban sustainability and sustainable cities idealizes a theoretical model made up of three integrated pillars: environment, economic, and social. This model suggests a balance between interconnected urban systems in advocating for a more comprehensive approach to sustainable planning solutions in cities. The sustainability planning 
paradigm recognizes the problematic nature of some of the past approaches to urban planning and seeks to regenerate urban landscapes to be more responsive to the natural environment, more economically vibrant, and more attractive places for active civic life. Furthermore, this paradigm advocates for increased mitigation of greenhouse gas emissions and adaptation to global climate change on a local scale (Boswell, Greave, and Seale, 2012).

Despite the widespread use of this three-pillar model, many challenges remain. Interpretation of the three-pillar model remains varied in theory and in practice. Of the three dimensions of the model, the social dimension remains the most underdeveloped in the literature, leaving practitioners with a lack of consensus on meaning, methods, and practices for addressing these challenges. As a result, deep urban social problems and inequities are increasingly prevalent, even in the most 'sustainable' cities or regions, despite the promise behind the ideology of sustainability.

This research aims to inform social sustainability theory and urban planning practice to begin to address these significant urban social challenges. As such, this research involves multi-site, comparative case studies of neighborhood-scale sustainability planning projects in Portland, U.S.; Copenhagen, Denmark; and Nagoya, Japan to bring to light an understanding of how the social dimension is conceptualized and translated to practice in different contexts, as well as the challenges planners, citizen participants, and other stakeholders encounter in attempting to do so. The 
following three chapters, which have been written as three separate manuscripts, aim to answer the following research questions:

- Chapter One: How has the social dimension of sustainability been defined, conceptualized, and translated to practice in district-scale sustainability planning in different political, economic and socio-cultural contexts? Are these current, innovative approaches considering social determinants of health (SDH) in their planning process and proposed outcomes?

- Chapter Two: What influences do political economic contexts have on the ways in which social dimensions are approached in different countries? What challenges do planners, citizen participants and other stakeholders encounter in attempting to plan for social sustainability? What are the similarities and differences across contexts?

- Chapter Three: Whose interests are being emphasized and whose interests are being overlooked throughout the planning process? How does cultural context influence this?

This research aims to inform theoretical notions of social sustainability from the ways in which urban communities are conceptualizing this contested dimension in their planning efforts, as well as the challenges they face along the way. Furthermore, this research aims to contribute to theory and planning practice by beginning to create a 
pathway for integrating the social determinants of health (SDH) framework with conceptualizations of social sustainability. 


\section{Chapter One:}

Interpretations of the Social Dimension of Sustainability in Urban Regeneration Practice: Application of a Social Determinants of Health Lens

\section{Abstract}

The concept of sustainability has been widely adopted in urban planning practice and theory. The social dimension of sustainability remains the most underdeveloped and overlooked dimension of sustainability, both conceptually and practically, though social aspects of sustainability offer great potential to address urban social problems. This paper reports on findings from research involving case studies of neighborhoodscale sustainability planning projects in Portland, Oregon; Copenhagen, Denmark; and Nagoya, Japan to describe the ways in which the social dimension of sustainability has been conceptualized and implemented in recent planning practice. The social determinants of health (SDH) framework is applied to these conceptualizations to identify the utility of this framework in further developing the social dimension of sustainability. Findings suggest commonalities across contexts and differences in their emphasis on structural and contextual determinants. This SDH framework contributes structure to theory on the social dimension of sustainability and provides a useful tool 
for planners to address complex urban social problems through neighborhood-scale sustainability planning practice.

\section{Introduction}

A lack of consensus remains with regard to defining the social dimension of sustainability in theory and in practice. This "concept in chaos" has left many urban planners and local governments scratching their heads when it comes to implementing this dimension in practice (Vallance, Perkins, \& Dixon, 2011; Littig and Griebler, 2005; Godschalk, 2004; Holden, 2012; Saha and Paterson, 2008; Zeemering, 2009). However, it is important to recognize the dangers inherent in historic approaches to urban planning that have failed to consider social sustainability. For example, particularly from the 1940 s through the 1960 s, communities in many cities in the U.S. experienced significant "slum clearance" in the inner city under the auspices of programs such as Urban Renewal (Massey and Denton, 1993). This initiative resulted in large-scale displacement of entire low-income and primarily African-American populations, severing deep community ties and deepening the racial segregation of American cities (Fullilove, 2004; Jacobs, 1961). This exclusion, along with race-based containment policies, such as redlining, created decades of ripple effects of social vulnerability and disparities in communities across the country, such as segregation, poverty, differential educational outcomes and health inequities (Massey \& Denton, 1993; Jackson, 1985; Williams and Collins, 2001). 
These negative social and health effects in American communities provide a context for understanding how planning decisions which fail to consider larger social structures and neighborhood social contexts result in an unsustainable urban social environment. As a result of this historical legacy, displacement and gentrification are common concerns resulting from sustainability planning today, which have largely been inadequately addressed in planning practice. Emphasizing the social dimensions of sustainability in urban planning plays an important role in reducing socio-spatial inequity, social vulnerability and health inequities. Addressing this gap in sustainability planning is a pressing concern.

This research aims to illuminate meanings of social sustainability found in neighborhood-scale urban planning projects and to begin to create a pathway forward for planning for social sustainability in urban communities. While the majority of the social sustainability literature attempts to define and describe the various elements of theoretical notions of the social dimension of sustainability, these case studies herein expand on this work in two important ways. First, the case studies explored here contribute a much-needed empirical perspective to this field by examining three ongoing urban planning projects to describe the ways in which they are actively attempting to address the social dimension of sustainability in urban planning practice. Second, this research employs a social determinants of health (SDH) lens to each of these planning projects to pinpoint areas in which planning interventions can support social sustainability. This lens targets elements of societal structure and community 
context that contribute to the reduction of social inequities and promote healthy community environments. This is the central goal of planning for social sustainability. Case studies of neighborhood-scale planning projects in Portland, Copenhagen and Nagoya will serve to answer two main research questions: 1) how has the social dimension of sustainability been defined, conceptualized, and translated to practice in district-scale sustainability planning in different political, economic and socio-cultural contexts? 2) to what extent are these current, innovative approaches considering SDH in their planning process and proposed outcomes? This analysis is the first of a three paper series exploring planning for social sustainability in these three neighborhood-scale projects. While this paper describes how these communities are conceptualizing the social dimension and applies an SDH lens, the second paper explores the nuances of political economic context on planning at the neighborhood-scale. The third paper, then, examines notions of social sustainability, such as social inclusion and nurturing a sense of belonging, as they relate to inclusion of diverse community actors, such as sexually oriented businesses and recent immigrants.

\section{Background + Review of Literature}

Although the majority of recent literature on social sustainability seeks to explain the meaning of the social dimension within the sustainability paradigm, a lack of consensus remains on how this important dimension is to be defined and operationalized (Littig and Griebler, 2005; Vallance, Perkins, \& Dixon, 2011). This 
dimension has been overlooked and under theorized in the sustainability literature, as the environmental dimension has taken center stage, often favoring technical fixes over comprehensive system changes that might disrupt the status quo or present political opposition.

Few studies have comprehensively examined how to address social sustainability within urban planning. In perhaps the most comprehensive attempt to evaluate social aspects of sustainability in urban planning projects, Colantonio and Dixon (2009) developed a set of indicators to measure social sustainability in urban regeneration projects in the EU. They argue that the literature on social sustainability is underdeveloped, lacks consensus on themes or indicators, and lacks guidance for translating theory to practice. Drawing on social theory and the fragmented social sustainability literature, Colantonio and Dixon (2009) present a social sustainability assessment framework that includes the following: demographic change; education and skills; employment; health and safety; housing and environmental health; identity, sense of place, and culture; participation, empowerment, and access; social capital; social mixing and cohesion; and well-being, happiness, and quality of life. The authors caution that urban social sustainability policies are experimental, fragmented and contested, highlighting the need for much more empirical work to be done in this area to support effective community interventions. While Colantonio and Dixon (2009) offer an important first step forward toward addressing social sustainability in urban planning contexts, this framework would benefit from a more comprehensive integration of 
structural factors within social organization that impact community health and wellbeing, such as income, social class, race and ethnicity. These factors have historically led to unsustainable social environments characterized by socio-spatial segregation and an uneven geography of opportunity.

The social determinants of health (SDH), which describe social institutions and processes that influence health (WHO, 2007; Carlson and Everett, 2013), provide a much needed, comprehensive framework for understanding the social dimension of sustainability. Benefiting from an abundance of social theory and health promotion research, the SDH lens is a valuable tool for examining the structural and contextual determinants in our society that affect individual and population health. Structural factors include income, education, employment, social status, gender, human rights, race, ethnicity, equity, and social justice. These structural determinants are the factors that are most commonly associated with societal inequalities and health disparities, which have been shown to produce negative outcomes for everyone along the social gradient (Wilkinson, 1996). Contextual factors include social environments, physical environments, personal health practices, healthy child development, health systems, access to health services, culture, and empowerment. These contextual determinants relate to the ways we plan for community systems that are supportive of health and well-being.

These structural and contextual factors provide important mechanisms to influence individual and population health and should be considered as such when 
planning for communities at various scales, especially at the neighborhood level. Neighborhoods are important social units that have significant influences on health and social well-being (Kawachi and Berkman, 2003). Furthermore, recent research has demonstrated that one's zip code is the best predictor of health status (Drewnowski, Rehm, and Solet, 2010). Another study found the gap in life expectancy for African American men between Washington, D.C. and the suburbs in Maryland to be approximately 17 years (WHO, 2008). Proactively planning for wellness in social conditions at the neighborhood scale can positively impact the health of the community and reduce inequitable disparities in health outcomes as a pathway to building social sustainability.

Directing policy and planning efforts towards addressing the SDH, the social institutions and processes that influence health, will be critical in the promotion of social sustainability (Carlson and Everett, 2013). Though the SDH framework has been applied in other contexts, it has only recently been applied to social sustainability policy (Baugh Littlejohns \& Smith, 2014). Baugh Littlejohns and Smith (2014) conducted a SDH template analysis of social sustainability policy documents in the Vancouver, B.C. metropolitan area. Their work found significant overlap in the goals and initiatives of the SDH and municipal social sustainability policy. However, intersectoral collaboration is needed to integrate and strengthen these efforts at multiple scales.

While the World Health Organization (2007) provides an overarching framework for the SDH, this case study research builds on the work of Baugh Littlejohns and Smith 
(2014), which brings these health promotion concepts into government-scale social sustainability policy, and incorporates the urban planning practice perspective of Colantonio and Dixon (2009). These concepts have yet to be coalesced into a clear framework that specifically integrates the SDH into framing of the social dimension of sustainability planning at the neighborhood-scale. The aim of this analysis is to begin to define a pathway for this integration.

\section{Methods}

Research Design

A multi-site, comparative and descriptive case study approach (Bernard and Ryan, 2010, p. 8; Yin, 2014) was selected to answer the following research questions: 1) How has the social dimension of sustainability been defined, conceptualized, and translated to practice in district-scale sustainability planning in different political, economic and socio-cultural contexts? 2) Are these current, innovative approaches considering SDH in their planning process and proposed outcomes? These questions will be answered here in an integrated fashion. As indicated by Flyvbjerg (2001) "the case study produces precisely the type of context-dependent knowledge which makes it possible to move from the lower to the higher levels in the learning process." Case study methods have also proven to be very useful in examining relationships between health outcomes and the SDH in urban settings (Ompad, Galea, Caiaffa and Vlahov, 2007). 
Case study methods included interviews with community stakeholders, participant observation and template analysis of planning-related documents. Variant cases were purposively selected to answer the primary research questions (Flyvbjerg, 2001). To ensure a diversity of contexts as well as some level of comparability, the following criteria were used to select an international, cross-cultural sample of three sites: 1) a first/developed world context - to facilitate comparison of implementation of this model in a similar development context; 2) a sustainability-focused planning project; 3) a neighborhood-scale urban regeneration or redevelopment project redevelopment of an urban district that was deemed to be in need of regeneration; 4) a project intentionally attempting to address aspects of social sustainability in their objectives (explicitly or implicitly); and 5) to provide more depth to our understanding of how context matters, as well as to compare innovations across regional contexts, one project from each of the following regions of the world was selected: North America, Asia and Europe.

Sites and Sample

Three case studies of neighborhood-level urban planning projects were conducted for this study. Based on the criteria discussed above, one project was selected from each of the following cities: Portland, Oregon, U.S.; Copenhagen, Denmark; and Nagoya, Japan. Using snowball sampling, interviews $(n=22)$ were conducted with community stakeholders involved in the planning project representing various perspectives at each site. Stakeholders included urban planners, community 
organization representatives, local business owners, marginalized populations, and community residents. Participant observation was conducted in each community at the street level, community events, and planning meetings. The template analysis involved review of planning-related documents from each of the case studies. Newspaper articles related to each case study were not included because the focus was on the ways in which the social dimension of sustainability is conceptualized from the perspective of the community stakeholders, rather than the media.

\section{Data Collection}

Data were collected at each of the study sites between June 2013 and November 2013. One key stakeholder, or gatekeeper, from each project was contacted via email and invited to participate in an in-person interview. Upon completion of this initial interview, each gatekeeper was asked to provide names and contact information for other community stakeholders, representing each of the various perspectives outlined above, who have been involved in the planning process in the community. Each stakeholder was invited to participate in an interview to be scheduled at a time and place of their choosing. Some participants extended invitations to attend events or meetings, such as a community-held flea market in Copenhagen, a Low-Carbon District Committee meeting in Nagoya, and a community outreach event to gather feedback on greenstreet improvements and show progress on the local park building project in Portland. These invitations allowed for opportunities to conduct unstructured participant observation. Additional participant observation was conducted at the street 
level. Field notes were written immediately following each observation. Gatekeepers were also asked for planning-related documents to be used to conduct the template analysis. The Copenhagen and Nagoya projects have detailed community visioning booklets for their planning efforts, while the Portland project does not have an allencompassing booklet for all of the various projects that make up their community planning initiative. In place of a visioning booklet, the Portland project provided several reports, a memorandum of agreement between the initiative's partner organizations, a fact sheet on the overarching initiative, performance indicators, and an anti-

displacement strategy report conducted in partnership with graduate students in urban and regional planning.

Interviews were conducted in English in Portland and Copenhagen. In Nagoya, the gatekeeper interview was conducted in English, and all other interviews were conducted in a combination of English and Japanese with the help of interpreters. All interviews were audio-recorded and transcribed. Interviews conducted in Japanese were translated and transcribed to English text by professional translators. Documents from Copenhagen were provided in English. Documents from Nagoya were provided in Japanese and translated to English by the professional translators.

Data Analysis

Grounded theory methods were used to analyze qualitative data gathered from interviews and observations. These data were coded using Dedoose QDA software. Codes were developed from research questions (defining the social dimension), 
interview questions (what this place is about), and community concerns that emerged from the data (unwanted land uses). Initial coding, followed by focused coding was used to sort and categorize data based on the meaning behind participants' perspectives (Charmaz, 2006). The analysis phase consisted of an iterative process guided by a systematic method of asking analytic questions of the data throughout the process. These questions included: 1) What's going on? (Lofland et al., 2006); 2) What is being said? What is not being said? What's missing?; 3) Whose interests are being emphasized? Whose interests are being overlooked? Analytic memos were written throughout the data collection and analysis phase to keep track of emergent meanings, themes and theories.

A SDH-influenced template analysis was conducted to analyze planning-related documents associated with each case study. Template analysis is a type of text analysis that uses a directed approach at analyzing text-based data (Hsieh and Shannon, 2005). This directed approach specifically begins with a codebook or template that is informed by existing literature or theory. In this study, the template was constructed from key framing documents pertinent to international conceptualizations of the SDH and conceptualizations of neighborhood-scale planning for social sustainability (WHO, 2007; Baugh Littlejohns and Smith, 2014; Colantonio and Dixon, 2009). Using an a priori template and codebook, the researcher runs the risk of not looking beyond the codes at contextual features that may be important to the social phenomena under study (Crabtree and Miller, 1992; Hsieh and Shannon, 2005). Therefore, the a priori template 
or SDH-influenced codebook was used to analyze the first six pages of each planning document (two from each case). During this process, memos were created to keep track of the fit of the codebook. Any necessary adjustments to the codebook were made before proceeding with the remaining documents. For example, under the structural determinants section of the codebook in the "income" category, the concept of "wealth" was added, as income is potentially temporary, whereas wealth-building through methods such as homeownership represents a greater potential for long-term stability. The resulting SDH-influenced codebook included a set of seven structural determinants and a set of nine contextual determinants, which are outlined in Table 1. Documents were analyzed page-by-page for inclusion of language or plans related to these determinants using the following rating system to determine the degree to which these factors are to be integrated: 0) not mentioned, 1) mentioned once, 2) mentioned and importance stressed or mentioned more than one time, 3) actionable ideas discussed, and 4) plan outlined and/or funding allocated (Lofland, et al., 2006). At the completion of document analysis, a summary was created by indicating the highest rating given over all documents for each of the determinant categories. A summary of these ratings was also calculated for each group of structural determinants and contextual determinants.

\section{Results}


The objective of this analysis is to delineate the extent to which these current, innovative neighborhood-scale planning approaches incorporate social determinants of health $(\mathrm{SDH})$ in their planning process and proposed outcomes. This section will demarcate conceptualization and implementation of social sustainability-related initiatives in practice as they relate to $\mathrm{SDH}$, and discuss the corollary findings generated by the SDH-influenced template analysis.

The Living Cully initiative in Portland, Oregon, U.S. integrates many common community development methods into their own version of an EcoDistrict (Seltzer, Smith, Cortright, Bassett, and Shandas, 2010). Living Cully conceptualizes and seeks to implement the social dimension of sustainability through a variety of structural determinants such as poverty-reduction through job training, development of employment opportunities, equity, environmental justice, and homeownership. Contextual determinants include anti-displacement, affordable housing, social cohesion, social inclusion, equity of access, empowerment, multi-generational involvement, diversity in citizen participation, physical and social gathering places, addressing "problem" businesses, promotion of "community-serving" businesses, honoring native epistemologies, and increasing the amount of greenspace to promote physical activity and connections to nature. As indicated by the template analysis, Living Cully places a greater emphasis on structural determinants than contextual determinants, as compared the other two neighborhoods examined (see Table 1). 
When asked what social sustainability means to this project and this community,

one participant spoke of environmental justice, social cohesion, inclusivity, and access

to decision-making processes.

I think it means environmental justice. And I think it means social cohesion so that the voices are represented and respected and there's access. It doesn't mean that everyone's going to be involved, but there's access for people to be involved, so there's an inclusivity to it that maybe you won't find everywhere. I would want to go see this in play and understand that: ok it's true, anyone could walk in these doors and find a place for themselves to have a moment at the table.

Framing the initiative in terms of environmental justice was echoed by another participant who stressed the importance of diverse representation in decision-making processes and the sentiment that Living Cully is writing a new story for environmental justice communities in the city.

I also see it as a justice movement. To balance everyone's needs in a way that makes sense both from an environmental and a social perspective is challenging. Living Cully is trying to do that in a mindful way of making sure people are at the table, that they know what's going on in their community, that they get a chance to say something about it, and are valued for that voice, much more than what I would call tokenism. Like, we're going to put this industrial facility in your backyard and yeah, you can come to a few meetings, but we don't care. I don't think that's the case. Living Cully has been built with a reputation and a presence in the community that that's not going to happen anymore.

One of the main avenues for implementing environmental justice-oriented initiatives is creating equity of access to amenities enjoyed in other, more prosperous or prominent neighborhoods. For example, Portland is known as an extremely park-rich city. Though Cully is geographically one of the largest neighborhoods in the city, it is significantly lacking in greenspace. This is a major concern for this community. Tired of 
hearing empty promises from the city government about community infrastructure improvements, the Living Cully partner organizations decided to take action on a grassroots level to create more greenspace for the neighborhood. The community began the lengthy process of redeveloping a brownfield site into a healthy, vibrant park. The partner organizations involved community members in every step of the process from working with the EPA to test methane emissions from the site to enlisting children at the local middle school to come up with various playground designs and working with the Native community to design a tribal gathering garden. Each step has been an exercise in capacity building for community members of all ages and backgrounds. As they work to build the park, Cully residents have learned about soil contamination, accessible design, Native history, and community gardening with the idea that the next time a park development project happens, these residents will have expertise to bring to the table, as well as transferable skills for other employment opportunities. One stakeholder described this philosophy of creating access to amenities through community action and capacity building.

We want every neighborhood to have opportunity. We don't want opportunity only to exist down here and then we don't have transportation to go down there. What we envision this region should have is healthy connected communities. We want Cully to be known as a community that's thriving and self-determined and are not afraid to roll up their sleeves and to grab a shovel right alongside making that happen. They're educated and they're informed and they're full of culture and life. And when you go to Cully, you feel that living, loving community. 
This stakeholder also draws a connection between neighborhood amenities and opportunity.

The built environment and access to healthy neighborhood amenities have significant implications for health and access to economic opportunities (Kawachi and Berkman, 2003). Cully is taking this very seriously by integrating opportunities for empowering participation, job training, employment opportunities, development of affordable housing, and community ownership into their planning efforts as key elements.

[Living Cully is about] demonstrating that you can take a particular project in a neighborhood and reduce poverty by the way that you create resources and bring prosperity to a neighborhood. And it's really a bottom-up structure, where you begin by asking the community, if you were to bring a significant project to the community? How would you want it to look? Would you want to work there? Would it meet the needs of your family? So these projects have done that, basically.

Though a heavy emphasis is placed on anti-poverty initiatives, Living Cully sees this as an integral part of sustainability. What they find to be of principal importance is the process through which the Living Cully EcoDistrict initiative is carried out and what is built through that process. This is a value that the partner organizations keep in mind with each of the projects that fall under the Living Cully umbrella.

That's the tagline is as an anti-poverty strategy. That's kind of paramount for us. We may or may not be able to create a lot of jobs in any given project but the attendant benefits of the way we do it and what we build are sort of a multiplier effect and we're just starting to like, wow, there's a lot of things that come under this rubric of when we try to look at sustainability as an anti-poverty strategy, like youth involvement and learning about sustainability and environmental technologies. Or people connecting with each other because they now have a place to gather. 
An important part of these processes is ensuring diverse representation of Cully residents in planning efforts, an important contextual determinant. Living Cully partners have taken great measures to increase the diversity of the voices at the decision-making table through measures such as hiring a diverse board and staff, paying honorarium to low-income and community residents of color, direct outreach to low-income residents and communities of color, and providing translation services to ensure inclusion of ESL residents.

Initiatives included in the Living Cully EcoDistrict project include negotiation of a Good Neighbor Agreement with Columbia BioGas, development of various types of affordable housing and an anti-displacement initiative to combat the effects of gentrification on low-income residents. The agreement between Columbia BioGas, a company in the process of creating an anaerobic digestion facility in the Cully neighborhood, and Living Cully partners included dedicated jobs for the community and maintaining the environmental health of the community. No strangers to environmental justice concerns, Living Cully partners and community members challenged Columbia BioGas to think about the social pieces of the project, such as community impact and job creation.

Affordable housing initiatives are primarily headed up by two Living Cully partner organizations, Hacienda Community Development Corporation and the local office of Habitat for Humanity. Community stakeholders describe affordable housing as "a long term social good" that allows low-income people to live closer-in to the central city, 
closer to jobs, and closer to urban amenities. Having a stable, affordable place to live, an important contextual determinant, affords families a solid foundation for building economic prosperity and health-full lives (Lubell, Crain, and Cohen, 2007). Living Cully partners have built a significant amount of affordable apartment units with amenities such as a community futsol court, community gardens and a tienda that provides access to culturally relevant foods for many community residents. Opportunities for home ownership are also available through Habitat for Humanity sweat equity programs, which provide opportunities for families to build wealth and longer-term prosperity, making a significant impact on structural determinants.

Sankt Kjelds is a pilot project that is developing an innovative approach to climate adaptation while integrating methods championed by Jan Gehl and his Cites for People ideals, such as creating vibrant public gathering places and interactive built environments, that can be seen often throughout Copenhagen (Gehl, 2010). The Sankt Kjelds Climate Quarter (SKCQ) in Copenhagen, Denmark shares some commonalities with the conceptualization articulated by Living Cully stakeholders, such as contextual determinants including social inclusion and representative participation in planning and decision-making. Overall, results of the template analysis indicate more of a balance between structural and contextual determinants, as compared to the other two communities (see Table 1). The SKCQ project began as a combined climate adaptation and urban renewal project, which includes bringing a "social lift" to the community. As many apartment units in the older buildings in the community still have shared 
bathroom facilities, one goal of the urban renewal project is to update the buildings so that each unit has their own facilities. Another aspect of the "social lift" is to work with residents to develop more of an identity and sense of belonging within the community by focusing on the culture of everyday life. This part of the project is called Culture House.

With Culture House, we decided to work with this everyday culture because we saw this area as, it has a high quality of life but people have to go away to do things so we wanted to find out how we can make a cultural life out here that will attract this everyday culture.

The SKCQ project vision emphasizes the overarching themes of Health and Motion with specific focus areas in contextual determinants such as, cooperation, activities, and meeting places. Visioning within this broad framework includes creating opportunities for neighbors to interact, accommodating the unique needs of different types of people, encouraging physical activity, and providing positive activities for youth. Implementation of this vision includes projects such as creating activity routes with nodes for physical activity and social interaction, development of public spaces for social gatherings, a culture laboratory with a project and media workshop, and a bike shed for young people to be involved in bike repair activities. Other projects emphasize encouraging behaviors that are beneficial to the environment through small community grants and partnering with a local environmental non-profit organization, working with students from a local university to integrate arts-based features designed to spur social interaction, and measures to integrate immigrants into the community. 
Project leaders have conducted outreach in the community by holding a number of focus groups with various population groups to understand how they use the community and to identify the things they'd like to see change. These focus groups have helped project leaders to target specific areas to prioritize and develop common activity routes to further enhance with nodes for social interaction and physical activity. The importance of making adjustments to accommodate the needs of older adults was one key lesson learned in this process. From something as minor as removing the heavy metal door at the entrance to the park to concentrating more necessary amenities in the small area frequented by many older adults who live in a care home in the neighborhood, these ideas have been incorporated into the planning project as a result of this community outreach and citizen participation.

A few of the project initiatives target structural determinant-specific social problems that the community is facing related to gender and race/ethnicity. Solutions are oriented toward contextual determinants to rebalance structural concerns. Throughout Copenhagen, it is very common for young girls to reduce their physical activity or involvement in sports at around 15 years of age. Copenhagen is also receiving many new immigrants who can easily be marginalized in Danish society. The project has been working to develop initiatives for conducting outreach, creating opportunities for physical activity, connecting social services with community residents, recruiting immigrant children for sports clubs, and opportunities for participation and integration. A program of activities has been established at the local park near buildings where many 
immigrants live to help them to meet people and integrate into the community, in addition to zumba fitness classes and other physical activities for young girls. The Culture House project also addresses a complex social problem at the local school by working to reduce stigma and bring the community in for activities to spur social inclusion and integration of students of color.

We're working to make an addition of the school with the culture house. Again, focusing on the everyday culture, focusing a lot on children's activities and activities that parents can do out there. It's Copenhagen's largest school but it has had a bad reputation, which means that a lot of the resourceful people in the area put their children to private schools. The school actually has a large intake from pupils from Nørrebro, which is a more, um, has some more problems. There are a lot of rumors about the school. One part of the goal of the cultural house is to get parents to use and see the school before they decide which school to go to so they can see that it's actually a good, well-functioning school and the dark people that they might see aren't, uh, shouldn't scare them or anything.

By having events at the school, leaders hope to expose more parents in the community to the school, which will hopefully reduce discrimination.

One key focus of SKCQ lies at the intersection of all of the dimensions of sustainability, which is promoting environmentally-oriented consumer behaviors among peers through programs led by a local environmental non-profit organization, called MiljøPunkt, which has partnered with the municipality's community planning efforts and established a local office in the neighborhood. MiljøPunkt provides regular communications, education and programming, including small grants to individuals or groups who have ideas for projects to encourage environmental behaviors in the home and community. For example, one individual has developed a system for teaching and 
providing materials for people to grow tomatoes in a small space to fit in the small apartments in the neighborhood. The idea is to reconnect with where food comes from, how much work it takes to grow food, promote healthy living and to encourage people to connect their behaviors to larger global effects. One representative feels that this approach, "gives a whole new perspective" and helps people to reimagine "a lot of new ways of how can we live in our cities." This community representative explains this perspective and connects this with having access to important everyday amenities close by and maintaining that access for future generations.

I guess expanding what I think creates my quality of life right now to the whole area, which is that, to be able to bike to work and have the kids in the kindergarten right next to my house. To be able to live and act very locally and still kind of understand a broader perspective, to be able to just for fun grow my own tomatoes and that they'll still have the chance to do that, even if they begin by doing it in a small two room apartment that there is somewhere close where they can go and plant a tomato, that there's an openness to use the city as you like but in a green way.

As part of the effort to increase social interactions and to create a greater sense of belonging in the community, an important contextual determinant, the initiative is trying several tactics. Among these are promoting a more vibrant street life, leveraging socialization that is already occurring within inner courtyards, blocking off streets to shift the focus from cars to public spaces for social interaction, and something called Human Hotel. In Copenhagen, the traditional style of apartment buildings are aligned to wrap around a common courtyard (see Figure 1). These courtyards provide exceptional social environments for residents of these buildings to engage with one another. 
However, the challenge for planners in this environment is that without many shops or other activities going on at the street level, it can be difficult to cultivate a vibrant street life on the outside of these buildings. As such, neighbors who live across the street from one another may never know each other. This representative explains this challenge here.

A very important aspect of the area is that we have some really large, very green and useful courtyards. The courtyards are open and have playgrounds, barbeque spots and stuff like that. A lot of people will spend their afternoons being social within this courtyard. They meet their neighbors there. That's another reason why it's a bit difficult to attract the same street life that you can do in the inner city.

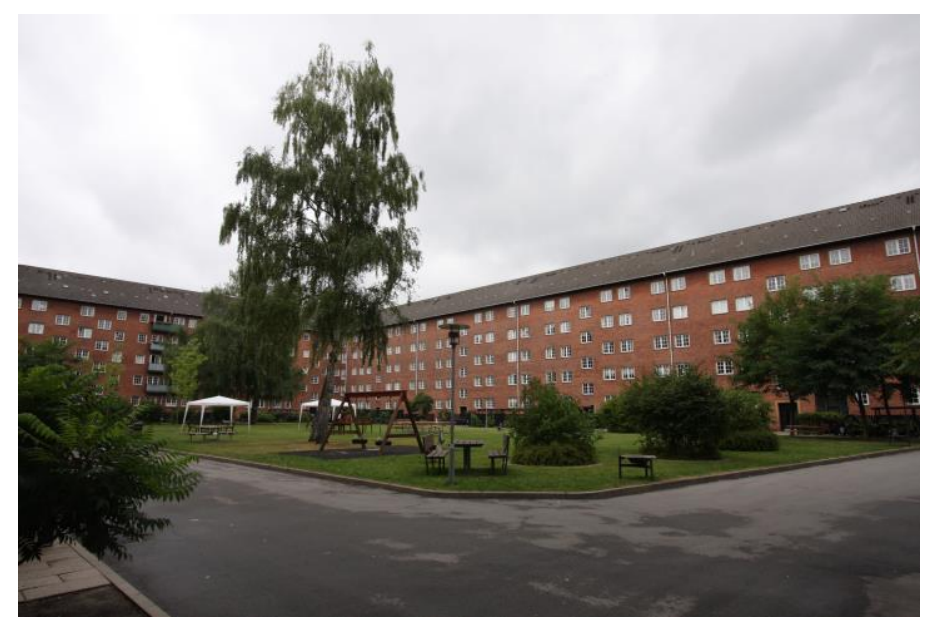

Figure 1: One of the larger inner courtyards in Sankt Kjelds.

The Human Hotel project, "which strives to make our Sankt Kjelds neighborhood the friendliest neighborhood in Copenhagen" expands the social environment of the community to create international connections but also to bring neighbors into one another's homes. 
Over the last six months, they've had international artists live with residents. So live there and produce art for a week and then have an opening in their apartment so kind of invite everybody inside this private apartment to see this art opening.

In the Chojamachi community in Nagoya, Japan, conceptualizations and implementation strategies of the social dimension of sustainability begin with a process called machizukuri (Murayama, 2007; Murayama and Sharifi, 2011; Sorenson, 2002, p. 308-332; Watanabe, 2007). This process is a community-driven civic engagement method that involves various groups from the community in developing a vision for the community and working toward implementation of the shared vision. Various groups who have been involved in the community planning process in Chojamachi are local business owners, older adults, and youth, as well as others in the community. One stakeholder explained that the machizukuri process is key to addressing the social dimension.

You will know by the atmosphere how this machizukuri has, actually the social dimension is very important and also through the project there are lots of normalization or we can kind of respond to things that were not responded before for many things. Projects that are going towards more social equity or advocating for people who are in need. It's like advocacy planning.

Machizukuri involves creative methods for harnessing local knowledge to honor the history of the community in planning efforts. These include arts-based activities, such as a karuta game commemorating the history and meaning of place and tanka, a style of poetry, with community elders to share their feelings about the meaning of place in Chojamachi. These examples of the process of machizukuri connect with the contextual 
determinants, while the outcomes of machizukuri planning connect to both structural and contextual determinants. Results from the template analysis indicate a slightly stronger emphasis on contextual determinants than the other two communities (see Table 1).

Because of the significant loss of population, both residents and businesses, in the community, a variety of initiatives in Chojamachi focus on recovering the population of the district through reuse of old buildings and co-housing or room-sharing, as well as temporary solutions to making use of the vacant spaces.

In order to recover the population of the district, and also use the old buildings, the project has been launched, which focuses on renovation of existing buildings and converts to residential units. Actually, there's one case already in which three or four people came together and renovated one floor of the building and they now live in that floor. Kind of a renovation and room-sharing project.

Other initiatives connected to contextual determinants have included painting shutters that cover permanently closed businesses, partnering with Aichi Triennale, a prefecturewide arts festival. As part of the Aichi Triennale festival, vacant spaces were used for gallery spaces throughout the district and a local artist decorated an old unused part of the local subway station to transform the decaying district into a more vibrant urban place.

In addition to recovering the population of the district, Chojamachi has "a general policy to have secured living for everyone, meaning different generations" (Chojamachi representative, November, 2013). As part of this policy, the community planning project has prioritized providing home-based services to support older adults 
through a local nonprofit organization through contract with the government. One of the larger initiatives toward this goal is a plan to develop an intergenerational housing community to provide a supportive, interdependent environmental for older adults and other members of the community. These initiatives are explained here by a community stakeholder.

The vision that we made in 2011, [includes a] policy of securing living for every generation. There is a non-profit organization initiative to take care of elderly people in the community in terms of providing food or checking whether they are safe. That kind of a community-based activities started. So, as I said the elderly people are the most vulnerable population. There's one person [who is] is trying to do some community-based business for elderly people who are in need.

Physical design plays an important part in facilitating social connectedness in a community, which demonstrates the interconnectedness of these contextual determinants. Chojamachi's physical design vision is to work to create more gathering spaces in the community. Over the years, the history of the community's physical infrastructure has shifted more towards larger building footprints, larger roadways to facilitate deliveries to and from fabric businesses, and few open spaces aside from parking lots. The district has no parks and approximately $40 \%$ of the public space is made up of roadways. This presents somewhat of a long-range design challenge in creating more places for social connections. The physical design plan focuses primarily on three initiatives: 1) narrowing the roadway to create more safe, vibrant spaces for people and less emphasis on cars, 2) creation of alleyways connecting kaisho, small public squares, to facilitate more social interactions (see Figure 2), and 3) a "wood 
utilization project" that aims to make use of the country's overabundance of forest products to provide softer wooden surfaces in the community as an alternative to the ever-presence of concrete, glass and steel in urban environments. These types of initiatives are intended to directly influence the social environment of the community and improve the quality of life. One stakeholder describes these important connections.

The wood utilization project...I don't know if it will create business prosperity. It's more like improving the quality of life. The public space in the city has become all steel and concrete... so this idea of using wood, now we have an excess of forest resources. By using trees, it enriches the public space. It'll make a good landscape, an enjoyable place to walk. That's connected to improving the quality of life in this town.

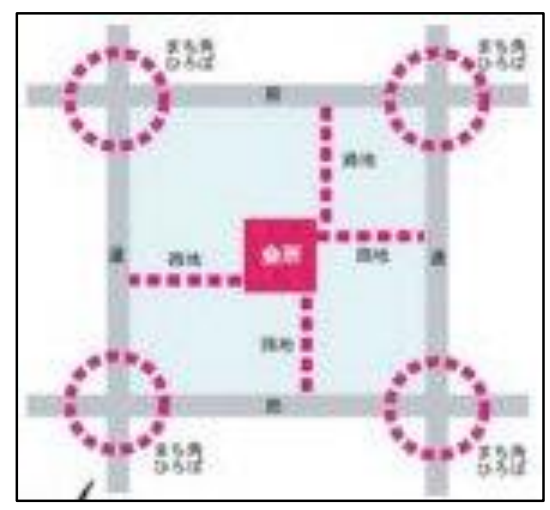

Figure 2 - Kaisho plan. Block redesign plan to integrate community gathering spaces into Chojamachi district. Red indicates future alleyways and community gathering spaces.

Community events and festivals are also important to improving quality of life and maintaining social connections. As a method for combatting the decay of the district, community leaders began holding an annual community festival to bring people together and honor the cultural history of community festivals practiced in many other cities and towns in Japan. They have found much success in bringing the community 
together around these events, particularly the annual Ebisu festival, even those who are not particularly involved in community planning efforts, as explained by one stakeholder below.

In planning for the annual Ebisu festival, many people are involved, including the restaurant owners because they have this common goal of holding this annual festival and making this a success. There are many people who do not care much about the overall community development effort but put a lot of effort into this one big event.

One stakeholder summarized the perspective shared by many in the community on the meaning behind the community planning efforts that really gets at the heart of the social dimension, including a focus on people, social connections and honoring the community history.

For me, it's about making this a city that people will live in. Becoming a city that people live in means... it won't become a business area, but it will be a place where connections between people are upheld, and this Chojamachi's history can only continue if people continue to live here. Because if they don't, the story can't continue. For me, machizukuri is about the people living in the town.

Findings from the SDH-influenced template analysis were consistent with findings from stakeholder interviews. As evidenced by the summary of the SDHinfluenced template analysis (Appendix A), the three projects take varied approaches to addressing the social dimension of sustainability. Living Cully in Portland, Oregon places a greater emphasis on structural determinants than the other two districts. Chojamachi in Nagoya, Japan places greater emphasis on the contextual determinants than the others. As for Sankt Kjelds in Copenhagen, Denmark, results reflect a balance between the two types of determinants, as compared to the approach taken by the other two 
districts. Considering the primary emphasis of the Living Cully initiative is that of an "anti-poverty strategy" that seeks to "address disparities in wealth, income, health and natural resources" (Living Cully Partner Organizations, 2013), this illustrates the attention being paid to contextual determinants of the SDH framework. For Chojamachi, the most homogeneous community of the three, the primary focus areas are on honoring the cultural and historical legacy of the community, creating meeting places to stimulate social interaction, developing an intergenerational housing community, and reimagining the use of physical spaces in the community for diverse, contemporary uses. In Sankt Kjelds, there is a balance between structural and contextual determinants. Their initiative emphasizes integrating immigrants in equitable ways, creating meeting places to stimulate social interaction, creating designated routes to encourage physical activity, and encouraging cooperation between various stakeholders and different types of residents.

\section{Discussion}

This analysis demonstrates that conceptualizations of social sustainability in each of these communities maps onto the SDH conceptual framework. While each of these communities has several initiatives that are shaped by the concept of "health," they have also developed initiatives that connect with the social institutions and processes that are integral to the SDH framework (Carlson and Everett, 2013). Though not explicitly using the terminology of $\mathrm{SDH}$, these communities have done the difficult work 
of developing conceptualizations and corollary initiatives that ultimately bring them to SDH principles. This finding has significant implications for social sustainability theory, for urban planning practice, as well as for the social well-being of these urban communities. This SDH framework presents an approach to reducing social inequity in structural and contextual elements of society, which has shown to benefit everyone in society (Wilkinson, 1996). The framework takes social sustainability theory beyond the "conceptual chaos" by identifying some concrete concepts through which to focus planning efforts (Vallance, Perkins, \& Dixon, 2011; Littig and Griebler, 2005).

Within these conceptualizations, several common themes arise among the interpretations of social sustainability within these planning contexts, such as social inclusion, built environment, local culture, and quality of life. Social inclusion plays a central role in each of these projects. This is implemented through outreach to different population groups, participation in planning activities, and developing projects that meet the diverse needs of different groups. The built environment is an important support system for the social environment. As such, creation of vibrant public spaces for social interaction is a key element in each project. Integration of local culture and arts plays an integral role through involvement in an art festival, incorporating artistdeveloped, interactive wooden furniture into the urban landscape, and development of a tribal gathering garden. While seemingly intangible, an emphasis on quality of life is perhaps the most broad but, arguably one of the most important elements of these 
community plans. The conceptualization of quality of life ultimately relates to achieving the overall shared vision of social sustainability for the community.

Similar to the work of Colantonio and Dixon (2009), this study finds that each community takes a locally-specific approach. Living Cully focuses more on the structural determinants than the other two projects. This is not surprising, given that community leaders are attempting to address bigger structural determinants on a daily basis, such as poverty reduction. As such, the structural determinants are where they need to focus their efforts, though many interventions at the structural determinant level require a mix of interventions related to contextual determinants. For example, supporting affordable housing initiatives to improve residents' chances of building wealth can provide an important social safety net and contribute to intergenerational socioeconomic mobility (Agyeman, 2013, p. 22).

In examining the utility of this SDH framework for urban planning practice, communities can use the SDH framework as a guide to consider the structural and contextual determinants and focus projects according to community needs. This community representative explains this prioritization of needs and the different approach afforded as a result of a lack of major social problems in the community.

Before, these urban renewal projects used to be in areas of Copenhagen where there were a lot of problems and you would kind of help them raise their living standards. But this area is actually quite, I don't want to say a rich area, but it's not an area with a lot of problems. There are of course different kinds of people living here with different incomes, but we don't have [a lot of] problems therefore in this community we have been able to focus on projects with the most social standard, social impact. We've been able to focus on some projects with some challenges that are for everyone in Copenhagen. Basically a lot of 
people living here do have the resources to engage in some of these bigger projects.

Considering the hierarchy of needs that applies to the community would be a useful first step. For example, when a community is relatively homogeneous and economically stable, it's possible that only focusing on the contextual determinants would suffice. If there's not as much of an issue with one determinant or a set of determinants, there may not be a strong need to focus energy there.

For some issues, the dimensions of sustainability are quite intertwined and difficult to disentangle. As such, there are elements of sustainability that should be examined in a broader whole-sustainability context. Socioeconomic factors transcend boundaries that may exist between dimensions. Social status and economic factors are intertwined in most societies and tend to determine the conditions of one's environment. Visioning in these communities necessitates an overarching approach.

From an economic perspective, there's prosperity in the community, that people have access to jobs both within the community that are meaningful and beyond. Good jobs with benefits, with retirement prospect, that type of thing.

The SDH framework accounts for these intertwined factors. However, there are other areas that are not accounted for in this SDH theoretical framework, such as encouraging environmental behaviors among peers and the complexities of the "social lift" described by Sankt Kjelds representatives. Falling at the intersection of the environmental, economic and social dimensions, consumer behaviors, such as sharing consumer goods rather then each person owning one or more of a particular product, are not considered in the social determinants of health framework. The "social lift" in Sankt Kjelds aims to 
raise living standards among those who share bathroom facilities. This is an example where a "social lift" can sometimes put social goals at odds with environmental goals. Though the community is not at a loss for water or other resources, providing each apartment unit with their own bathroom facilities may increase water consumption and the use of building resources. Future research could explore these intersecting wholesustainability challenges.

\section{Limitations}

This project provides a cross-section of in-progress planning projects. At a different time point, these perspectives might be different or might become limited by practical restrictions. What is envisioned is not necessarily what happens in planning practice. The best intentions do not always turn into the best plans and the best plans don't always turn into the best realities. As such, this analysis covers what is envisioned and what is included in long-range plans.

In terms of research design, using a gatekeeper for each project could mean that some perspectives are reflected in this research while others are intentionally or unintentionally left out. Furthermore, as a cultural outsider or simply a community outsider, others may be unable to understand shared, unspoken cultural meanings, in addition to understanding beyond the language and cultural barriers. While this research provides some insight into meanings of social sustainability and inclusion of social determinants of health across different contexts, there are many more varieties 
of contexts out there to be examined. Future research could aid in understanding differences and similarities across contexts.

The template analysis approach is not without limitations. This approach presents a challenge to the naturalistic paradigm; using existing theory means that the researcher is approaching the data with an informed but strong bias (Hsieh and Shannon, 2005). An overemphasis on theory can blind the researcher to other contextual elements that may not be covered by the theoretical framework. Some of the categories within the template analysis could be broken down more and analyzed on a micro scale. For example, the Social Environments category covers things like social mixing, networks, cohesion, and social capital. This is very broad and could be interpreted as social diversity and as built environment that encourage social interaction. Furthermore, just because a particular topic is not discussed doesn't necessarily mean it is not an area of concern or emphasis. For example, the concepts of well-being, happiness and quality of life may not be mentioned directly but initiatives such as creating more gathering spaces and affordable housing may contribute to a higher quality of life.

\section{Conclusion}

This study describes the ways in which the social dimension has been conceptualized and translated to practice in various neighborhood-scale planning projects. By focusing in on the social factors that promote health and viewing 
communities through a social justice lens, the SDH perspective provides a framework for understanding and addressing the social dimension of sustainability, particularly those structural and contextual factors that are more relevant to the given context. This framework contributes an important structure to the "conceptual chaos" of social sustainability theory (Vallance, Perkins and Dixon, 2011) and provides practitioners with a structure for planning for social sustainability on a neighborhood-scale while also addressing mechanisms for reducing health disparities. 


\section{References}

Agyeman, J. (2013). Introducing Just Sustainabilities: Policy, Planning, and Practice. Zed Books; NY, NY.

Baugh Littlejohns, L. \& Smith, N. (2014). Building bridges between health promotion and social sustainability: an analysis of municipal policies in Western Canada. Local Environment, 19, 4, 449-468.

Bernard, H.R. and Ryan, G.W. (2010). Analyzing Qualitative Data: Systematic Approaches. Sage Publications: Thousand Oaks, CA.

Carlson, M. and Everett, M. (2013). Social Sustainability and the Social Determinants of Health: Understanding the Connection. In: Social Sustainability: A Multilevel Approach to Social Inclusion. Ed. Veronica Dujon, Jesse Dillard, Eileen M. Brennan. New York, NY: Routledge.

Charmaz, K. (2006). Constructing grounded theory: A practical guide through qualitative analysis. Thousand Oaks, CA: Sage Publications.

Colantonio, A. and Dixon, T. (2009). Measuring socially sustainable urban regeneration in Europe. Oxford Institute for Sustainable Development, pp. 1-129.

Crabtree, B. and Miller, W. (1992). Doing Qualitative Research. Newbury Park, CA: Sage Publications, Inc. 
Drewnowski, A., Rehm, C., and Solet, D. (2010). Disparities in obesity rates: Analysis by ZIP code area. Social Science \& Medicine, 65(12), p. 2458-2463.

Flyvbjerg, Bent. (2001). Making Social Science Matter: Why social inquiry fails and how it can succeed again. Cambridge, UK: Cambridge University Press.

Fullilove, M. T. (2004). Root Shock: How tearing up city neighborhoods hurts America, and what we can do about it. New York: One World Books.

Gehl, J. (2010). Cities for People. Washington, D.C.: Island Press.

Godschalk, (2004). Land use planning challenges: coping with conflicts in visions of sustainable development and livable communities. Journal of the American Planning Association, 70 (1) (2004), pp. 5-13.

Holden, M. (2012). Urban Policy Engagement with Social Sustainability in Metro Vancouver. Urban Studies, 49(3), 527 -542. doi:10.1177/0042098011403015.

Hsieh, H. and Shannon, S. (2005). Three approaches to qualitative content analysis. Qualitative Health Research, 15, 1277-1288.

Jacobs, J. (1961). The death and life of great American cities. New York: Random House. Jackson, K. (1985). Crabgrass Frontier. New York: Oxford University Press.

Kawachi, I. and Berkman, L. (2003). Neighborhoods and Health. New York: Oxford University Press. 
Littig, B., \& GrieBler, E. (2005). Social sustainability: a catchword between political pragmatism and social theory. International Journal of Sustainable Development, 8, 65-79.

Lofland, J., Snow, D., Anderson, L., \& Lofland, L. (2006). Analyzing social settings. $4^{\text {th }}$ ed. Belmont, CA: Wadsworth Press.

Living Cully Partner Organizations. (2013). Living Cully: A Cully Ecodistrict. Fact sheet from Living Cully Partner Organizations.

Lubell, J., Crain, R., and Cohen, R. (2007). Framing the issues: The positive impacts of affordable housing on health. Center for Housing Policy.

Massey, D. \& Denton, N. (1993). American Apartheid: Segregation and the Making of the Underclass. Cambridge, MA.: Harvard University Press.

Murayama, A. \& Sharifi, A. (2011). Low-Carbon Strategy and Community Development in Nagoya, Japan: Case of Nishiki 2 District, a Fabric Warehouse District in Transition. Conference Proceedings, EcoDistricts Summit, October 27, 2011, Portland, Oregon.

Murayama, A. (2007). Civic Movements for Sustainable Urban Regeneration: Downtown Fukaya City, Saitama prefecture. In Sorenson, A. and Funck, C. (eds.) Living Cities in Japan. New York, NY: Routledge. 
Ompad, D. C., Galea, S., Caiaffa, W. T., \& Vlahov, D. (2007). Social determinants of the health of urban populations: methodologic considerations. Journal of Urban Health: Bulletin of the New York Academy of Medicine, 84, 3, 42-53.

Saha, D., \& Paterson, R. G. (2008). Local Government Efforts to Promote the "Three Es" of Sustainable Development. Journal of Planning Education and Research, 28(1), 21 -37. doi:10.1177/0739456X08321803.

Seltzer, E., Smith, T., Cortright, J., Bassett, E., and Shandas, V. (2010). Making EcoDistricts: Concepts and Methods for Advancing Sustainability in Neighborhoods. Report for the Bullitt Foundation, 1-122.

Sorensen, A. (2002). The Making of Urban Japan: Cities and planning from Edo to the twenty-first century. Nissan Institute/Routledge Japanese Studies Series: New York, NY.

Vallance, S., Perkins, H. C., \& Dixon, J. E. (2011). What is social sustainability? A clarification of concepts. Geoforum, 42(3), 342-348.

Watanabe, S.J. (2007). Toshi Keikaku vs. Machizukuri : Emerging paradigm of civil society in Japan, 1950-1980. In Sorenson, A. and Funck, C. (2007). Living Cities in Japan : Citizens' Movements, Machizukuri and Local Environments. Nissan Institute/Routledge Japanese Studies Series : New York, NY.

Wilkinson, R. (1996). Unhealthy Societies. The Afflictions of Inequality. Routledge ; 
London.

Williams, D. and Collins, C. (2001). Racial Residential Segregation: A Fundamental Cause of Racial Disparities in Health. Public Health Reports, Sept-Oct, Vol. 116, p. 404416.

World Health Organization. (2008). Commission on Social Determinants of Health. CSDH Final Report: Closing the Gap in a Generation: Health Equity Through Action on the Social Determinants of Health. Geneva, Switzerland: World Health Organization.

WHO (2007). A Conceptual Framework for Action on the Social Determinants of Health. Commission on Social Determinants of Health. Retrieved at: http://www.who.int/social determinants/resources/csdh framework action 0 $\underline{5 \text { 07.pdf?ua }=1}$

Yin, R. (2014). Case Study Research: Design and Methods. Fifth edition. Thousand Oaks, CA: Sage Publications, Inc.

Zeemering, E. S. (2009). What Does Sustainability Mean to City Officials? Urban Affairs Review, 45(2), 247 -273. doi:10.1177/1078087409337297. 


\section{Chapter Two:}

"And then it goes political":

The Contested Political Economy of Planning for Social Sustainability in Urban Neighborhoods

Abstract

Sustainable development is comprised of environmental, economic and social dimensions, however, conceptual agreement on defining and implementing the social dimension has not been reached. Scale and context are key components in planning for social sustainability, yet few studies have examined the impact of political economic contexts, particularly at the neighborhood-scale. This study is a comparative exploration of impacts of political economic context on neighborhood-scale urban planning projects on three continents, Portland, US; Copenhagen, Denmark; and Nagoya, Japan. Emergent themes from community stakeholder interviews include distrust in government, effects of political priorities on income inequality, contested perspectives on social welfare, and community efforts to "teach the city." This analysis in different but comparable economic and political contexts highlights key dynamics of planning at the neighborhood scale. Findings contribute to greater conceptual clarity for the social 
dimension of sustainability and facilitate efforts to incorporate social sustainability in planning practice.

\section{Introduction}

While it is commonly accepted that sustainable development is comprised of three main pillars - environmental, economic, and social -- scholars have been working to develop greater knowledge and understanding about the complexities of the social pillar of sustainability, particularly in urban planning contexts (Littig and Griebler, 2005; Vallance, Perkins, and Dixon, 2011; Godschalk, 2004; Holden, 2012; Saha and Paterson, 2008; Zeemering, 2009; Dillard, Dujon, and King, 2009; Polese and Stren, 2000). Much of the social dimension of sustainability scholarship is at the formative stage of describing and defining concepts, as well as illuminating the social processes and institutions that are important to this dimension (Carlson and Everett, 2014). As scholars attempt to define social sustainability, though there is no clear consensus, we can see some common overarching themes, such as equity, fairness, social justice, wellbeing, quality of life, social relationships, meeting human-scale needs, and a focus on the collective functioning of urban life. However, few studies have contributed to understanding factors associated with political economic context that facilitate or challenge the path toward planning for social sustainability, particularly at a neighborhood-scale. There is general agreement that the social dimension of sustainability is context-specific (Lehtonen, 2004). As such, it is important to examine various contexts and their specific political economic dynamics to understand how the social dimension is considered from 
different contextual perspectives. Learning from various contexts about commonalities, as well as those dynamics that differ, may inform and deepen our understanding of this realm of sustainability and aid urban planners in their work to create sustainable communities.

\section{Background + Review of Literature}

Government decisions on public policy, though not generally connected to health outcomes, have profound effects on the health and social wellbeing of their constituent populations, even at the neighborhood level (Bryant, 2010; Navarro and Shi, 2001). Provision and affordability of health services, availability and affordability of housing, income distribution, and policies that support working families are some examples of determinants shaped by policy arenas that can have dramatic consequences for population health and wellbeing (WHO, 2008; WHO, 2007). Health and wellbeing are key components of social sustainability (Colantonio and Dixon, 2009), as such, national political economic context crucial to consider in planning for social sustainability at the neighborhood-scale. Many intractable challenges are rooted at a complex, political economic scale, which can be defined as the scale at which political and economic orientations in society converge to impact public policy. This structural context of society remains a significant challenge for neighborhood efforts to plan for social sustainability. 
Political economic structures such as neo-liberal, social democratic, and postauthoritarian reflect differences in the level of inequalities, public spending on social and economic supports, and population health in societies (Bryant, 2010; Navarro and Shi, 2001). Neo-liberalism, or a market-dominant model, assumes that markets most effectively and efficiently distribute resources with an underlying emphasis on competition and 'rugged individualism' among producers and consumers. In this type of winner-take-all environment, as Coburn (2000) argues, social cohesion, trust and collectivist views of society amongst citizenry are low. Public policy in neo-liberal democracies is shaped by the values and ideals of society, thereby re-enforcing dominant individualistic notions of society and further intensifying inequalities produced by the market system. These inequalities in society produce differential levels of health status among the population (Wilkinson, 1996).

Conversely, the welfare state was developed as a system that attempts to correct for market fluctuations and the resultant inequalities. Public policy in welfare state systems is designed to institutionalize mechanisms for social and economic security across the lifespan, despite changes in individual health status, life transitions, employment conditions and family planning. As such, welfare state policies are designed to boost social cohesion, encourage collective functioning of society and to flatten out economic divisions in society in favor of population health and well-being (Coburn, 2000). 
Other case studies of urban sustainability planning have described contexts in great detail, yet few delve into the dynamics associated with political economic context in planning for social sustainability on a neighborhood-scale. Moore (2007) highlights the significant ways in which political dynamics shape the road toward the "story" of sustainability in different contexts. However, his analysis focuses primarily on the municipal and regional levels, with little attention paid to planning at smaller scales and the challenging factors associated with the neighborhood-scale. Cuthill (2010) takes a metropolitan regional approach involving diverse stakeholders to develop a social sustainability framework in response to rapid urban growth. Cuthill's work provides a useful step forward for engaged governance, yet does not delve into challenges of political economy or venture beyond the regional scale. Colantonio and Dixon (2009) focus their inquiry on measuring aspects of social sustainability in the urban regeneration projects at the neighborhood-scale in the E.U. Though their focus is on the neighborhood-scale, it is also primarily on measurement, therefore political economic context is largely absent.

This research examines three case studies in sustainable urban community planning, each in a different political economic context. Neighborhood-level community planning projects in Portland, Oregon; Copenhagen, Denmark; and Nagoya, Japan provide the backdrop for understanding the nuances of planning for social sustainability. As part of a three paper series, the first of which describes how these communities conceptualize and implement concepts of social sustainability through planning 
practice, this second paper aims to address the following questions. First, what influences does political economic context have on the ways in which social dimensions are approached in different countries? Second, what challenges do planners, citizen participants and other stakeholders encounter in attempting to plan for social sustainability? What are the similarities and differences across contexts? This paper is followed by a third paper, which takes to task ideals of social sustainability such as social inclusion and nurturing a sense of belonging with regard to diverse neighborhood actors, such as sexually-oriented business and recent immigrants. In this second paper analysis, the cross-national research perspective allows us to examine how factors related to political economic context affect the perspectives of local stakeholders in planning for social sustainability. This study is unique in that it uses a cross-cultural, cross-national comparison to examine how local and national context influence social aspects of sustainability in neighborhood level planning practice.

\section{Methods}

Case study research methods were used in three neighborhood-level planning contexts: Portland, Oregon; Copenhagen, Denmark; and Nagoya, Japan. These particular projects were selected because they met the following criteria: 1) a first-world or developed-world context for comparison purposes; 2) a sustainability-focused planning project; 3) a neighborhood-scale urban regeneration project; 4) a project intentionally attempting to address aspects of social sustainability in their objectives (explicitly or 
implicitly); and 5) a differing political economic context to understand challenges in different structural settings. Case study methods included interviews, participant observation, and template analysis of planning documents. In-person interviews $(n=22)$ were conducted in each community with stakeholders involved in each planning project representing various perspectives at each site: urban planners, representatives from community organizations, local business owners, marginalized populations, older adults, and community residents. Participant observation was conducted in each community at the street level, including public events and planning meetings. Building on the work of Baugh Littlejohns and Smith (2014) and Colantonio and Dixon (2009), a social determinants of health-influenced template was constructed and used to review planning documents from each sustainability project (summarized in Kohon, 2015). Data analysis

Grounded theory methods were used to analyze qualitative interview data and field notes from participant observation. Data were coded using Dedoose QDA software. Codes were developed based on research questions (defining the social dimension), interview questions (what this place is about), and community concerns that emerged from the data (unwanted land uses). Initial coding, followed by focused coding was used to sort and categorize data based on the meaning behind participants' perspectives (Charmaz, 2006). The analysis phase consisted of an iterative process guided by a systematic method of asking analytic questions of the data throughout the process. These questions included: 1) What's going on? (Lofland et al., 2006); 2) What is being 
said? What is not being said? What's missing?; 3) Whose interests are being emphasized? Whose interests are being overlooked? 4) How does the socio-political, cultural, and economic context affect framings of the social dimensions? Analytic memos were written throughout the data collection and analysis phase to keep track of emergent meanings, themes and theories.

\section{Results}

One of the main objectives of this research is to exemplify the ways in which context affects framings of social sustainability. This section will introduce the local context of each of the three cases and discuss themes related to the following research question: What influences does political economic context have on the ways in which social dimensions are approached in different countries? Using grounded theory methods, themes that emerged from data were distrust in government, effects of political priorities on deepening income inequality, contested perspectives on social welfare, and community efforts to "teach the city." These themes will be discussed following an introduction to the local and national context of each of the three case studies.

Each of the neighborhood-scale planning projects examined started with a significant set of challenges that community stakeholders wanted to address on a very local level through urban planning initiatives. In the Cully neighborhood of Portland, a socially, politically and physically marginalized community aimed to reinterpret the 
notion of sustainability celebrated in other parts of the city to gain greater social equity and economic stability. In the Sankt Kjelds Climate Quarter of Copenhagen, increasingly heavy rains indicating a significantly changing climate necessitated a shift in thinking about the built environment and its relationship to water, as well as a need to build resilience through strengthening social connections between different groups of people in the community. In the Chojamachi community of Nagoya, significant economic shifts in the fabric wholesale industry left this traditional community in decay, economically and socially. Though they all share an intention to address social sustainability, the local and national context in each place requires a tailored approach to urban planning.

\section{Living Cully - Portland}

As a result of a history of neighborhood-level mistrust of the city government, the Living Cully initiative started as decidedly grassroots. Initiated by community organizations in the Cully neighborhood, Living Cully began as a critique to the way the city was "doing" sustainability in other communities. City annexation of Cully came with the promise that services and infrastructure improvements, such as sidewalks and paved streets, would follow. Years of promises unfulfilled bred mistrust and a feeling that Cully was on its own if the community wanted to see physical change, much less any upgrades that other neighborhoods had already received, such as bioswales or bike lanes. 
The Cully neighborhood has a high concentration of low-income residents, people of color and recent immigrants, as well as a significant concentration of industrial businesses. Living Cully, currently a partnership between four non-profit organizations, prides itself on being an "anti-poverty" neighborhood-scale sustainability initiative. Some of their key initiatives follow a community development model including connecting low-income and people of color communities with green jobs through job training, preventing displacement of low-income residents through community ownership, and development of affordable housing through sweat equity and other programs. The Living Cully initiative is bringing an environmental justice community into the sustainability movement through the creation of environmental wealth for the community, such as the creation of nature areas and a large community park that was thoughtfully converted from a brownfield site in partnership with the U.S.

Environmental Protection Agency (EPA). Just as government officials and representatives of non-profit organizations are paid to carry out this kind of work, the Living Cully partners encouraged active citizen engagement in the development of the community park by paying participants a stipend and providing childcare during community events.

Living Cully stakeholders explain that their initiative has been heavily influenced philosophically by the Native community and the Relational Worldview Model. This model, developed by the National Indian Child Welfare Association in the 1980s, emphasizes a non-linear balanced view of the interdependence of the relationships 
between context, mental, physical and spiritual influences (NICWA, 1997). This

perspective effects the ways in which an individual interacts with the world. One Cully resident from the Native community describes this here.

Sustainability is talked about a lot nowadays. Sustainability is old for Native people. It's fundamental to everything we do traditionally as Native Americans. You can't sustain anything if you don't have balance and balance is also talked about as equity. You can't have sustainability without equity and you can't have equity if you don't ask the peoples what equity looks like for them and close those gaps for the disparities that exist. For me, that's just fundamental to what we do. When those elements come into play, then families benefit and individuals are enriched by that experience. It's optimum.

This Relational Worldview perspective is one of the driving ideals behind the Living Cully initiative and helps to frame their conceptualization of sustainability. From this perspective, balance is key. Therefore, any disparities that exist between social groups must be remedied in order to achieve sustainability.

The Living Cully initiative sees itself as compensating, at the neighborhood-level, for a national, neo-liberal context that does not support its neediest residents. As for national economic policies that support working families, the United States lags far behind other OECD countries (Bryant, 2010). The U.S. guarantees no paid leave to women in connection with childbirth, no paid maternity, paternity or parental leave, no paid annual leave, does not guarantee working mothers the right to breast feed, or paid sick leave (with the exception of FMLA-eligible organizations) (Harvard School of Public Health, 2004). A disproportionate number of Cully residents are among those most 
marginalized by these public policy decisions. Recognizing the cycle of poverty and the deepening economic divides in American society and in the Cully community, Living Cully's "anti-poverty" approach prioritizes and acts strategically to create a brighter, more stable future for many of its residents through job training, skill building, affordable housing, community capacity building, and empowerment.

\section{Sankt Kjelds Climate Quarter- Copenhagen}

The Sankt Kjelds Climate Quarter (SKCQ) project, in Copenhagen, Denmark, is a mainly top-down effort led by the municipality. The SKCQ planning project emphasizes civic cooperation, creation of meeting spaces in the community, and development of activities, including social activities and mechanisms to increase physical activity among residents. The SK project has brought in local artists to create interactive art pieces with which to create interaction between residents. Various efforts aim at building a meaningful identity or sense of place for the community beyond being the mixedincome, bedroom community just beyond the inner city that it has been. Giving the community a "social lift" includes upgrading the historic apartment buildings with shared bathroom facilities to modern individualized amenities.

Though the municipality funds and leads the project, they have established a local planning office and community space in the Sankt Kjelds community and recognize the need for local buy-in and collaboration. They have partnered with and share office 
space with a local environmental organization that encourages and educates local communities about everyday environmental behaviors in the home. The project office also offers small grants to local residents to lead sustainability-oriented initiatives in the community. Project leaders have conducted research in the community with local residents about how they use the community, including activity routes of older adults with differing mobility levels, as well as how various population groups would like to see the community change.

This local context exists within the municipal context of Copenhagen and the national context of Denmark. Being the most cosmopolitan city within one of the most socio-politically progressive countries in the world has a significant impact on the policies of the municipality. Unlike the U.S., climate change is scarcely debated in Denmark and funding priorities are decided accordingly. Particularly given the context of several years of increasingly heavy rains leading to urban flooding in Copenhagen, the municipality has dedicated significant funding to climate adaptation planning within the central city. This SKCQ project is a pilot project, part climate adaptation and part urban renewal or "social lift," which, if successful, will pave the way for many future projects of its kind throughout the city.

Denmark's political economy is commonly framed as an advanced social welfare state. All citizens have access to nationalized health care, government-provided childcare support, government-mandated paid maternity and paternity leave, guaranteed paid sick leave, substantial unemployment coverage, and a generous 
pension system. Denmark has also been rated as the happiest country on Earth (Helliwell, Layard and Sachs, 2013). With an historically largely homogenous populous, concerns related to a recent influx of immigrants has challenged some of these social welfare ideals and Danes are beginning to rethink their generous social safety net policies as a result (Roemer and Van der Straeten, 2006).

\section{Chojamachi - Nagoya}

The Chojamachi community in central Nagoya has a long history as a fabric warehousing and wholesaling community. Traditionally, business owners lived on the top floor of the low-rise buildings where they worked, while workers lived on the level just below them. Fabric shops and warehousing took place at the street level, creating a vibrant, mixed-use community of kimono makers, fabric sellers, workers, and residents. Over the last several decades, the social life of the community has begun to unravel. Suburbanization brought business owners to larger living spaces in the outskirts of the city, the bubble economy in Japan forced some businesses to close, and the forces of globalization further impacted the fabric industry. The emergence of companies like Uniqlo and Muji, which rely on supply chains and manufacturing of garments in developing countries, has resulted in the closure of many traditional fabric and textile businesses in places like Chojamachi in developed countries. Fearing the worst, many business owners have demolished their buildings and paved their land to create hourly 
parking lots, providing them with more consistent income. Yet, the creation of these vacant urban spaces further unravels the social fabric of the community and the absence of buildings for housing and economic revival makes it much more difficult to rebuild the vibrant social fabric that once existed. As a result of all of these changes, the Chojamachi community has experienced significant community decline, disinvestment, and loss of community social ties.

Rather than bottom-up or top-down, the community revitalization effort here has come primarily from the middle of the community power hierarchy. Long-time business owners make up the majority of the key community stakeholders in Chojamachi, though a non-profit organization has been established with community revitalization as priority one and strong relationships have been developed with local urban planning academics. Citizen engagement in Chojamachi involves various, locally specific community development activities, commonly known in Japan as machizukuri (Murayama, 2007; Watanabe, 2007; Murayama and Sharifi, 2011; Koizumi, 2004). Some initiatives in the Chojamachi neighborhood-scale planning project include diversification of businesses and creative reuse of existing buildings to create an economically resilient community, development of intergenerational housing to support the unique needs of the dramatically increasing older adult population, experimenting with shared living and working spaces, and creating more gathering places in the community. To bring more people into the community, Chojamachi partnered with Aichi Triennale, a prefecturewide art festival, to temporarily use the vacant community spaces as art galleries, both 
indoors and outdoors. This partnership literally put Chojamachi back on the map for many Aichi prefecture residents and international visitors alike.

The national context in Japan is currently in a state of flux. While the Japanese government has been known as a government that provides for its constituents through a national health care service, a comprehensive pension system, and other important social safety nets, a long period of economic stagnation has presented significant challenges to previously afforded comforts. Deepening economic inequality is palpable and some communities, such as Chojamachi, are attempting to find ways to address the gaps at a local level. For example, a community stakeholder developed ideas for supporting older adults in the community who have difficulty with important activities of daily living, such as shopping, cooking, and engaging in social interactions, including reintroducing traditional methods of communication that encourage regular social interaction and concern for wellbeing among neighbors.

Within these dynamic national and local political economic contexts, these three communities are attempting to plan for social sustainability. These ongoing urban planning projects help to inform our understanding of how context and scale create nuanced tensions in planning for the social dimension of sustainability. The following section will discuss emergent themes from interviews with community stakeholders in each case study context. 


\section{Mistrust in Local Government}

These three urban planning projects indicate the dynamic relationship neighborhoods have with their local government. While Sankt Kjelds is a top down project initiated by the municipality of Copenhagen, Living Cully is quite the opposite, and Chojamachi represents a middle ground, with the planning efforts initiated by local businesses. Each of these perspectives comes with benefits and challenges.

Alternatively, grassroots or community-initiated efforts such as Living Cully and the Chojamachi project have been developed as a response to government inaction or an historical relationship with local or even national government that has been paved with distrust. In Japan, economic stagnation and a shift toward greater neoliberaloriented policies over many years has necessitated a shift from reliance on government institutions to civil society taking on more community-based efforts. The participatory approach of machizukuri, a varied collection of community-engaged planning activities, has supplanted much of the previous government responsibilities. A stakeholder explains this shift in thinking and that this recent transition toward citizen engagement through machizukuri has provided a new pathway for local change.

In Japanese society now, we cannot trust government anymore. People started to realize and now they try to make their own effort to make the environment better. So, that's kind of the good influence of machizukuri in social aspect.

Similarly, Living Cully began out of a mistrust of local government and recognition that the City was not adequately addressing local needs.

It was annexed in ' 85 with the promise from the city that infrastructure 
improvements would come along with annexation and they never did so only $34 \%$ of Cully streets have sidewalks.

As the Living Cully initiative started to gain momentum and word began to spread through city channels, the Portland Bureau of Planning and Sustainability (BPS) offered support. Living Cully organizers were grateful for the attention and offer but felt that they were not ready to accept the city's offer, rather that they would wait until they had something for which they really needed support from BPS to achieve. Soon came the idea of creating an anaerobic waste digester in a thoughtful partnership with Columbia BioGas. This local company and their new facility would bring jobs and other community benefits, as per the Community Benefits Agreement signed by the company and Living Cully partner organizations. Living Cully organizers reached out to BPS to help with whatever they could do to support the development of this facility. One city official explains how the community's mistrust of local government has been turned into community action.

So [normally], the city makes the plan and the community engages and hopefully the plan melds to that engagement. Living Cully turns that on its head, it's like the people's plans and people execute it so then you don't need the city...W We either get on the bus or we get hit by the bus. I feel like that to me showed the power of community activism to get the city in line.

While having the blessing (and funding) of the municipality can be quite beneficial, such as in the case of Sankt Kjelds, local buy-in and participation is necessary for making lasting change to a community's social conditions. Much of the land that the municipality plans to use for the development of water catchment spaces and for transformation into public gathering spaces is owned by local housing co-operatives. 
The municipality and SKCQ project leaders are tasked with working with the housing boards and individual owners to get approval on their plans. While some neighborhood residents are active participants in the planning project, the barrier of community buy-in still exists. At any point in time, residents could oppose the project, leaving project leaders to retool their efforts.

\section{Political Priorities and Deepening Income Inequality}

When faced with the challenge of addressing social sustainability on this neighborhood-scale, many communities are forced to confront deepening social inequities that are rooted at a much larger scale than that of the neighborhood. Creating a sustainable community can be quite prescriptive on the environmental side, but when confronting the intersections of the economic and social dimensions, community leaders are met with significant questions and much larger-scale concerns than they can reasonably address within the boundaries of a neighborhood. While Living Cully prides itself on taking an anti-poverty approach to community sustainability planning, the challenges of that reality can at times seem insurmountable.

It's a fundamental question of our nation. We're a nation of haves and have nots and that is fundamentally unstable. We might be really sustainable on the environmental side but completely unsustainable on the social side.

As such, community leaders find others' approaches to community sustainability planning that overemphasize the environmental dimension to be shortsighted. Though 
these inequities are rooted in much deeper systems of oppression and political priorities seem to only exacerbate the problems while failing to recognize the externalities of reactive approaches, Living Cully is taking a proactive approach at incorporating social and economic perspectives.

These costs that we're going to incur by not addressing income inequality. You've got your stormwater taken care of but you're paying out all this money to incarcerate young black men. Someone's going to pay for that. Can we avoid the cost of incarcerating someone through job training them? The answer is yes.

In Chojamachi, community leaders have seen recent shifts in economic and political conditions creating deeper economic inequality. Community leaders are only beginning to grapple with this new reality. Cultural norms of not directly discussing inequities have inhibited the process of articulating plans for social and economic sustainability.

It used to be that we are all middle classes without disparities of income. Nowadays, there are actually many disparities and things that are not taken care of very well. We have a culture of not hiding but not explicitly expressing about that. But for aspects of environment or economy, we usually express or clearly state in our planning documents.

Sankt Kjelds leaders face challenges with the contentious position of recent immigrants in their community. While Denmark has been a fairly homogeneous society, the presence of new immigrants introduces challenges to former methods of community planning. SKCQ project leaders agree that their project is a bit of a luxury project because they're not dealing with a lot of politically contentious issues in this 
particular community. Comparing SKCQ to another project in a neighboring district, the following stakeholder quote describes the futility of addressing social sustainability using physical planning strategies, particularly with a politically contentious population such as "homeless foreigners."

The urban renewal is going to renovate that park but the trouble is you can do whatever you want physically. There's still going to be a shelter for homeless foreigners next door and they're still going to be every evening waiting to get in so people aren't going to use that park for sunbathing or whatever. You would have to propose something to take care of the social problem and then it goes political.

\section{Perspectives on Social Welfare}

Community stakeholders find that the reaches of social welfare within a given national context extend to the neighborhood-scale. Planning for social sustainability at this scale requires understanding to what extent citizens' health, family, and social service needs are supported by national social welfare-oriented policies.

Within these three case studies, Denmark arguably provides the most comprehensive support for its citizens through a national health care system, paid maternity and paternity leave, and childcare support, as a few examples. As mentioned, Denmark has also been rated as the happiest nation in the world (Helliwell, Layard and Sachs, 2013). Among a few other factors, Danes often discuss this comprehensive system of support and safety nets when asked about the causes of their happiness. Comparisons to the lack of support many Americans experience are common, as 
exemplified by one stakeholder.

I think the main source of our happiness is that we don't have to worry about anything because, the crime rate is really low and if you break your leg, you go to the hospital and it doesn't really affect you, which in the States, it might ruin you.

Another stakeholder noted that, in addition to nationalized health care, community planning projects also commonly emphasize aspects of social sustainability, such as living conditions and the needs of the people in the city.

It's a very easy country to live in, everything is taken care of, pay high tax, but if you're sick you can go to the doctor, to the hospital, and you don't have to pay. You don't have to have insurance. And projects like this, there's a lot of focus on the living conditions and the people in the city.

In Japan, the shift toward community-based planning has also extended to health and social welfare, particularly for older adults living in community settings. Community leaders are trying to find innovative ways of caring for older adults who may be limited in mobility, such as providing home delivery of fresh produce and recreating traditional systems of communication between members of a community.

We want to bring back the old style of Japanese communication. The Japanese cultural community, the feeling of osekai where people are involved in each others' lives. Older people NEED this kind of system. The system like that, with too much kindness, is good for elderly people.

In contrast, national healthcare reform in the U.S. has not come soon enough or comprehensive enough for residents of Cully. Unable to rely on a fragmented health system, community stakeholders include various types of social welfare support, which are currently commonplace in Denmark, in their visioning of a socially sustainable 
community. A Cully stakeholder envisioned an ideal:

Everyone who wanted healthcare would have healthcare. They would have access to childcare and other services that were of the community and by the community so that they met the true needs.

\section{Teaching the City}

Within each of these projects, community leaders find themselves pushing the boundaries of what local governance will support. These communities are challenging the status quo to move towards social sustainability in their neighborhoods and beyond. Chojamachi leaders wanted to install wooden decks and benches along the street to create more gathering spaces to encourage social interactions. The city responded by stating that because there was no precedent for such a project, they would not permit it. Convinced that this was a project that would contribute to social sustainability in the community, a local business allowed for the wooden decks to be built on their private property as a demonstration for the city. Chojamachi is teaching the city of Nagoya that creating socially sustainable communities requires thinking outside of the box and taking some minor risks.

Living Cully stakeholders found a way to teach the city of Portland how to conduct an inclusive, community oriented process for building a park in Cully. Rather than just involve the City parks department in the development, the community wanted to be actively engaged and have a say in what their park would be like. Living Cully partners enlisted students from the local middle school to work with professional 
designers to come up with playground designs. As part of the brownfield cleanup process, community participants were paid honorarium for their time working through the lengthy process of cleaning up the site, including measuring methane exhaust and achieving EPA standards. The community also pushed traditional boundaries and funding priorities by aiming to implement natural play areas and creating a tribal gathering garden.

Both Chojamachi and Living Cully have redefined the role they have with the city. Rather than simply accepting the conditions set by city officials or accepting the status quo, these communities have found creative ways to challenge the top-down hierarchical system of urban governance. Recognizing the flaws in the system that prevent these communities from achieving their visions of social sustainability, such as a built environment that facilitates social interaction and community planning processes that are inclusive of a diverse representation of community members, these communities took matters into their own hands. In the process, these experiences both addressed their immediate project needs and also redefined the nature of their relationship with the city, thereby engaging the city in shared governance. As such, Chojamachi and Living Cully have attempted to fill the gaps between neighborhood context and local government policy in achieving social sustainability goals.

Since the Sankt Kjelds Climate Quarter project is driven and funded by the municipality, teaching the city takes a different perspective in Copenhagen. The integration of urban renewal with a social lift and climate adaptation measures is a new 
model for the city of Copenhagen, as for many other places. The SKCQ is a pilot project designed to integrate these approaches into an innovative model that can be used in other areas of the city that are facing similar challenges, both with creating socially sustainable communities and addressing urban flooding or other climate adaptation concerns.

\section{Discussion}

National level political economic context plays an important role in planning for social sustainability on a neighborhood-scale. Income distribution, affordable housing, provision of health care, employment support, and other social welfare policies have dramatic impacts on the social needs of local communities (Coburn, 2000). These policies dictate how much and the types of support individuals and families within a community need to achieve health and wellbeing; key elements of social sustainability. Policies that support redistributive efforts have shown to support greater health of populations as they address crucial social determinants that would otherwise be left up to economic chance (Navarro and Shi, 2001). As such, social sustainability efforts, even at the neighborhood-scale must also take into account the inequalities in our society that result from uneven policy supports.

Urban planners in various contexts must navigate these important domains to be effective in their work to create sustainable communities. However, as noted by Agyeman and Evans (2003, p. 48), primarily with regard to the U.K. and U.S. systems, 
these urban planning practitioners are all too often "attempting to address social and ecological concerns within an unsustainable and unjust economic system." In a sense, these urban planners and community stakeholders are taking a gamble at making change in a system where the deck is stacked against them. Davidson (2010) questions whether the ideology of sustainability is another method through which to continue prioritizing economic growth, an unsustainable concept in and of itself, though a central priority in neo-liberal political economic contexts. Furthermore, some problems are more "wicked" than others. While policymakers and planners may be able to address problems and structural challenges incrementally, the depth and breadth of many social problems may prove to be insurmountable. Achieving social sustainability remains an ideal that, as Moore (2007) describes of sustainable cities, may remain a storyline, rather than a measurable finish line.

As such, practitioners are left with few tools to affect change at this larger, more complex national political economic scale, particularly when the focus of their efforts is narrowed to neighborhood-scale thinking. As Godschalk (2004, p.5) observes that "like acrobats without a net, land use planners are working on the frontiers of sustainability and livability practice, without the benefit of a profession-wide consensus on standards and methods." Yet, many local stakeholders find themselves staring down the barrel of these larger societal problems that are beyond their purview and funding capacity. Awareness and advocacy at the national governance level is an important step in addressing some of the challenges raised here. Partnering with public health 
practitioners and community development practitioners can help to support their work through targeting interventions and advocating for public policy at local and national government levels.

Though very few cities tackle the issue of social sustainability at a municipal or regional scale, one metropolitan region of note with regard to social sustainability policy is Vancouver, British Columbia. Holden (2012) discusses the work of Metro Vancouver's regional Social Issues Subcommittee, primarily made up of social planners from various municipalities in the region, in developing an overarching framework for social sustainability policy in the region. The region faced challenges in policy implementation, such as lack of funding for programs to address many dimensions and lack of capacity to address many of these larger social challenges. However, this effort represents a step forward in bridging gaps between the neighborhood-level and the national context. Perhaps with congruent funding allocated across various scales from provincial or national government levels down to urban planning initiatives such as the cases described here, social sustainability policy implementation could be successful.

\section{Limitations}

In delving into the context within which socially sustainable neighborhoods can be developed, there are certainly limitations. This study included a small sample of stakeholders from each community for a total sample of twenty-two participants. This sample may or may not be representative of the voices or opinions of all community 
members. Furthermore, this study represents only three cases of neighborhood-scale urban sustainability planning projects. Other projects may have different experiences and different perspectives to offer to the study of planning for social sustainability. Each of these cases represents an ongoing planning project, it remains to be seen how successful they are at their efforts to bridge the gap between local needs and national context.

Many more contexts must be examined to fully understand the impacts of political economic context on planning for social sustainability. The cases under study here represent a first-world context in three countries, three cities, and three neighborhoods. There are endless other contexts to learn from in the development of methods for planning for the social dimension of sustainability.

\section{Implications for future research}

Given that these communities are all in developed world or first world contexts, using this case study method with communities in developing world contexts could provide more depth to our understanding about how different development contexts influence the social dimension of sustainability. Also, the Danish experience of being rated as the happiest country in the world raises questions about how research on happiness and wellbeing may contribute to the development of our understanding and conceptualization of what social sustainability is and how to plan for it at various scales. Understanding how other neighborhoods in other contexts are able to teach or redefine 
their relationships with the city might be instructive for future social sustainability planning, especially in the absence of social sustainability policy at other scales. Future research could also delve into whether differences by political economic context can be mediated by advocacy and public policy efforts. The nature of urban contexts is that they are dynamic systems with entrenched histories rich with cultural, social and political uniqueness. Future research could investigate to what extent social sustainability policies can integrate these differences effectively.

\section{Conclusion}

Political economic context presents complex challenges that local stakeholders must grapple with when planning for social sustainability at the neighborhood-scale. A nuanced approach is necessary in each context because factors related to locality, histories and public policy are at play. Planners are charged with bridging gaps that exist between political economic structural processes and the neighborhood-scale. While neighborhood stakeholders can teach the city much in terms of community needs, expectations, and cultural contexts for decision-making for urban regeneration projects, shifting the societal and economic imbalances might require new planning models that integrate local, regional, state and national economic and social policies. 


\section{References}

Agyeman, J., \& Evans, T. (2003). Toward just sustainability in urban communities:

Building equity rights with sustainable solutions. The ANNALS of the American Academy of Political and Social Science, 590(1), 35 -53.

doi:10.1177/0002716203256565.

Baugh Littlejohns, L. \& Smith, N. (2014). Building bridges between health promotion and social sustainability: an analysis of municipal policies in Western Canada. Local Environment, 19, 4, 449-468.

Bryant, T. (2010) Politics, public policy, and health inequalities. In Bryant, T., Raphael, D., and Rioux, M. (Eds.). Staying Alive: Critical Perspectives on Health, Illness, and Health Care. 2nd Edition. Canadian Scholars' Press Inc.: Toronto, CA.

Carlson, M. and Everett, M. (2013). Social Sustainability and the Social Determinants of Health: Understanding the Connection. In: Social Sustainability: A Multilevel Approach to Social Inclusion. Ed. Veronica Dujon, Jesse Dillard, Eileen M. Brennan. New York, NY: Routledge.

Charmaz, K. (2006). Constructing grounded theory: A practical guide through qualitative analysis. Thousand Oaks, CA: Sage Publications. 
Coburn, D. (2000). Income inequality, social cohesion and the health status of populations: the role of neo-liberalism. Social Science \& Medicine, 51(1), 135146. doi.org/10.1016/S0277-9536(99)00445-1.

Colantonio, A., \& Dixon, T. (2009). Measuring Socially Sustainable Urban Regeneration in Europe. Oxford Institute for Sustainable Development, pp. 1-129.

Davidson, M. (2010). Sustainability as ideological praxis: The acting out of planning's master-signifier. City, 14 (4), p. 390-405.

Dillard, J., Dujon, V., and King, M. (2009). Understanding the Social Dimension of Sustainability. New York: Routledge.

Godschalk, (2004). Land use planning challenges: coping with conflicts in visions of sustainable development and livable communities. Journal of the American Planning Association, 70 (1) (2004), pp. 5-13.

Helliwell, J., Layard, R. and Sachs, J. (2013). World Happiness Report 2013. United Nations.

Heymann, J., Earle, A., and Hayes, J. (2004). The Work, Family and Equity Index: Where Does the United States Stand Globally? Institute for Health and Social Policy. McGill University.

Holden, M. (2012). Urban Policy Engagement with Social Sustainability in Metro Vancouver. Urban Studies, 49(3), 527 -542. doi:10.1177/0042098011403015. 
Kohon, J. (2015). Interpretations of the Social Dimension of Sustainability in Urban Regeneration Practice: Application of a Social Determinants of Health Lens. Unpublished manuscript.

Koizumi, H. (2004). Empowerment in the Japanese planning context. In Sorensen, A., Marcotullio, P. and Grant, J. Towards Sustainable Cities: East Asian, North American and European Perspectives on Managing Urban Regions. Ashgate: Hampshire, England.

Lehtonen, M. (2004). The environmental-social interface of sustainable development: capabilities, social capital, institutions. Ecological Economics, 49(2), 199-214. doi:10.1016/j.ecolecon.2004.03.019.

Littig, B., \& GrieBler, E. (2005). Social sustainability: a catchword between political pragmatism and social theory. International Journal of Sustainable Development, 8, 65-79.

Lofland, J., Snow, D., Anderson, L., \& Lofland, L. (2006). Analyzing social settings. $4^{\text {th }}$ ed. Belmont, CA: Wadsworth Press.

Moore, S. (2007). Alternative Routes to the Sustainable City: Austin, Curitiba and Frankfurt. Lexington Books; Lanham, MD.

Murayama, A. (2007). Civic Movements for Sustainable Urban Regeneration: Downtown Fukaya City, Saitama prefecture. In Sorenson, A. and Funck, C. (eds.) Living Cities in Japan. New York, NY: Routledge. 
Murayama, A. \& Sharifi, A. (2011). Low-Carbon Strategy and Community Development in Nagoya, Japan: Case of Nishiki 2 District, a Fabric Warehouse District in Transition. Conference Proceedings, EcoDistricts Summit, October 27, 2011, Portland, Oregon.

Navarro, V. and Shi, L. (2001). The political context of social inequalities and health. Social Science and Medicine, 52(3), 481-491.

Polese, M. and Stren, R. (2000). Social sustainability of cities: Diversity and the management of change. University of Toronto Press: Toronto, Canada.

Roemer, J. and Van der Straeten, K. (2006). The political economy of xenophobia and distribution: The case of Denmark. Scand. J. or Economics, 108(2), 251-277.

Saha, D., \& Paterson, R. G. (2008). Local Government Efforts to Promote the "Three Es" of Sustainable Development. Journal of Planning Education and Research, 28(1), 21 -37. doi:10.1177/0739456X08321803.

Vallance, S., Perkins, H. C., \& Dixon, J. E. (2011). What is social sustainability? A clarification of concepts. Geoforum, 42(3), 342-348.

Watanabe, S.J. (2007). Toshi Keikaku vs. Machizukuri : Emerging paradigm of civil society in Japan, 1950-1980. In Sorenson, A. and Funck, C. (2007). Living Cities in Japan : Citizens' Movements, Machizukuri and Local Environments. Nissan Institute/Routledge Japanese Studies Series : New York, NY.

Wilkinson, R. (1996). Unhealthy Societies. The Afflictions of Inequality. Routledge ; 
London.

World Health Organization. (2008). Commission on Social Determinants of Health. CSDH Final Report: Closing the Gap in a Generation: Health Equity Through Action on the Social Determinants of Health. Geneva, Switzerland: World Health Organization.

WHO (2007). A Conceptual Framework for Action on the Social Determinants of Health. Commission on Social Determinants of Health. Retrieved at: http://www.who.int/social determinants/resources/csdh framework action 0 5 07.pdf?ua $=1$

Zeemering, E. S. (2009). What Does Sustainability Mean to City Officials? Urban Affairs Review, 45(2), 247 -273. doi:10.1177/1078087409337297. 


\section{Chapter Three:}

Who Belongs in the Neighborhood?

Negotiating Social Inclusion and a Sense of Belonging in Planning for Urban Social Sustainability

\section{Abstract}

Developing sustainable communities requires urban planners and community organizers to make decisions that affect environmental, economic and social systems. The most underdeveloped of these dimensions remains social sustainability. Communities are met with complex challenges when negotiating concepts of social sustainability, such as social inclusion and nurturing a sense of belonging. This project examines three case studies of neighborhood-scale planning projects in Portland, Oregon, U.S.; Copenhagen, Denmark; and Nagoya, Japan. Each community is confronting challenges that further blur the lines of what it means to cultivate social sustainability, such as inclusion of sexually oriented businesses and immigrant groups. Emergent themes include negotiating contested land uses, integration of the disenfranchised, and marginalization of the marginalized. Notions of social sustainability are complicated by active inclusion 
or exclusion of the truly marginalized. This study raises questions of representation, rights to the city, and NIMBY attitudes in planning for sustainable communities and highlights inherent subjectivities in planning for socially sustainability.

\section{Introduction}

The path toward creating sustainable communities is paved with myriad challenges. As scholars continue to debate theoretical definitions and actions relevant to the social dimension of sustainability (Vallance, Perkins and Dixon, 2011), communities are attempting to negotiate the inherently subjective nature of theoretical concepts that define socially sustainable communities. Social inclusion and cultivating a sense of belonging have been identified as important components of social sustainability (Dempsey, Bramley, Power, and Brown, 2011). In practice, on the other hand, given common examples of neighborhood actors who present challenges to urban planning processes, such as sexually oriented businesses and recent immigrants, these ideals are confronted with conflict in the process of planning for social sustainability. Questions arise over who should be included, who should feel that they belong and to what lengths community leaders should go to achieve these ideals. In essence, planning for social sustainability begs the question: for whom and at what expense?

This study explores three case studies of neighborhood-scale sustainability planning projects in Portland, Oregon, U.S.; Copenhagen, Denmark; and Nagoya, Japan to describe how these communities are grappling with the challenges of planning for social sustainability. This analysis is part of a three paper series, the first of which 
describes how these communities conceptualize and implement concepts of social sustainability through planning practice. The second paper explores the influence of political economic context on planning for social sustainability at the neighborhoodscale. The analysis in this third paper seeks primarily to answer the question: Whose interests are being emphasized and whose interests are being overlooked throughout the planning process? This study seeks to inform social sustainability theory from the challenges faced in including marginalized groups in urban planning practice. The two main marginalized groups that emerged in these case studies were sexually oriented businesses and recent immigrants. As such, these two groups will take center stage in this analysis to facilitate understanding of the ways in which ideals of social sustainability can forsake one another. Exploration at the neighborhood-scale aids in interrogating ideals of social sustainability that are complicated by proximity, values, and competencies of communities to connect action at the neighborhood-level with larger visions of social sustainability.

\section{Background \& Literature Review}

Though social sustainability is conceptually contested, social inclusion and sense of belonging have been identified as key elements of creating social sustainability in urban communities (Dempsey, Bramley, Power, and Brown, 2011). Social exclusion, which can be seen as the opposite of social inclusion, has been defined by Levitas et al. (2009) as such: 
Social exclusion is a complex and multi-dimensional process. It involves the lack or denial of resources, rights, goods and services, and the inability to participate in the normal relationships and activities, available to the majority of people in society, whether in economic, social, cultural, or political arenas. It affects both the quality of life of individuals and the equity and cohesion of society as a whole. (p. 9)

Social exclusion is impelled by unequal power relationships at different levels of society, such as interpersonal, intergroup, community, national, and global (Taket et al., 2014). While creating a socially inclusive environment where people feel a sense of belonging may be a theoretical ideal, the reality of working toward this in urban communities is quite complex and fraught with contradictions. On the ground, communities working toward social sustainability are confronted with placing diverse community actors, such as sexually oriented businesses and recent immigrant populations, into their planning processes and negotiating their position within or outside of the community's dominant vision.

The field of planning has long debated contested land uses, such as sexually oriented businesses in urban neighborhoods. Locally unwanted land uses (LULUs) (Popper, 1981), such as sexually oriented businesses, mental health hospitals, detention centers, substance abuse treatment facilities, industrial facilities, and waste management facilities, have been confronted with a variety of NIMBY (Not In My Backyard)-directed interventions from picketing and protests to official complaints to city government and land use zoning restrictions. While most would agree that many of these types of LULUs perform necessary or perhaps inevitable functions of urban 
society, few communities accept them into their corner of the city with open arms. Challenges to LULUs are often grounded in assumptions of nuisance and negative externalities associated with the type of business, workers, or patrons they attract who are generally assumed to have come from outside of the community. Resistance, regulation, and exclusion of sexually oriented businesses are tools of the social production of space (Papayanis, 2000), reinforcing a heteronormative moral geography (Hubbard, et al., 2013). Some communities have found that stated intentions of protecting vulnerable neighborhoods from the "blight" of sexually oriented businesses have masked attempts to pave the way for gentrification (Hubbard, 2008; Papayanis, 2000).

Planning processes have also struggled with managing diversity and the incorporation of marginalized groups, such as recent immigrants, in urban neighborhoods (Fincher and Iveson, 2008). Language and cultural barriers are common roadblocks to actively including recent immigrants in community life and in planning processes. Furthermore, in an environment with limited resources, available resources are more likely to be spent on the dominant group. The nuanced needs of immigrants, such as translation, interpretation, culturally relevant outreach, and inviting community spaces are then further marginalized. Xenophobia, racism and classism often cloud judgment on a local community level. Though the stated community goals for social sustainability may involve social inclusion, many representatives of the community power structure are members of the hegemonic class and race (Day, 1997; Levine, Fung, 
and Gastil, 2005). All too often untrained volunteer community members lack the relevant cultural competency to do the hard work of authentically including immigrant groups in community planning at levels beyond tokenism (Arnstein, 1969).

Though sexually oriented businesses and immigrant groups are usually (though not always) distinct groups, their experience in community life shares some commonalities. Both groups experience stigma and discrimination. Both groups experience perceptions and assumptions of others placed upon them. Both groups are commonly viewed as outsiders when it comes to planning for the future of their communities. Disinterest in participatory community processes by both groups is commonly attributed to personal choice rather than to failures of community social structure, institutional cultures, or institutional processes to make space for social inclusivity. Feelings of stigma and discrimination may, in turn, interfere with access to services and social support networks further fueling social isolation (Krieger, 1999).

Social exclusion of certain groups in urban communities raises the notion of the 'Right to the City' originated by Henri Lefebvre (1991) and since invoked by others, such as David Harvey (2003). The right to the city describes the right for urban dwellers to reenvision and remake the city and, in the process remake themselves and urban society. With this power to carve out the social and physical urban places we inhabit comes struggles of democracy, representation and political power oftentimes resulting in processes of socio-spatial marginalization, particularly of minority demographic groups (Fincher and Iveson, 2008). The urban landscape then becomes one of functional 
segregation and spatial injustice. Representation across a geography of unequal power relationships results in uneven spatial governance.

As such, carving out notions of sense of place is highly subjective and valueladen. Notions of sense of place in urban communities are products of the individuals who in habit and interact in the space. However, perspectives on positive sense of place values can change over time and can be lost, changed, or reinterpreted (Norton and Hannon, 2004, p.358). What one individual values as a positive, healthy sense of place, such as a place where youth can grow up safely with positive influences, can contradict what another individual values, such as freedom of expression. Furthermore, the value of a place can change with a change in land use. If a particular parcel was once a contaminated brownfield, which is then transformed into a community park, the sense of place and the value of that space can be transformed in the eyes of individuals or even the community as a whole.

With the focus on developing sustainable cities and a recent interest in creating socially sustainable communities, these long-standing challenges in urban planning contexts are re-examined in this new context. What does it mean to create a socially sustainable community? Recent theory on social sustainability would advocate for social inclusion and nurturing a sense of belonging. Questions remain that challenge these simplistic notions, such as: Who belongs in a socially sustainable neighborhood? This analysis examines three case studies to explore the inherent challenges of social 
inclusion and nurturing a sense of belonging in urban communities, particularly with regard to sexually oriented businesses and recent immigrants.

\section{Methods}

Research Design

This research involved case study methods including interviews with community stakeholders, participant observation, and template analysis of planning documents. As one of the research aims, this study addresses the following research question: Whose interests are being emphasized and whose interests are being overlooked throughout the planning process?

The multi-site, comparative and descriptive case study approach (Bernard and Ryan, 2010, p. 8; Yin, 2014) was selected to help to develop a deeper understanding of the challenges faced in addressing social dimensions of sustainability in neighborhoodscale sustainability planning projects. Variant cases were selected through which to answer the primary research questions (Flyvbjerg, 2001). Three projects have been purposively selected because of their intentional approaches to addressing social dimensions in sustainable neighborhood-scale planning. To ensure a diversity of contexts, yet ensure comparability, the following criteria were used to select an international, cross-cultural sample of three sites: 1) a first/developed world context - to facilitate comparison of implementation of this model in a similar development context; 
2) a planning project that states the use of the three-pillar sustainability model as guiding principles; 3) a neighborhood-scale urban regeneration project - redevelopment of an urban district that was deemed to be in need of regeneration; 4) a project intentionally attempting to address aspects of social sustainability in their objectives (explicitly or implicitly); and 5) to provide more depth to our understanding of the importance of context, as well as to compare across regions, one project from each of the following regions was selected: North America, Asia and Europe.

Planning-related documents associated with each case study were analyzed using template analysis. In order to analyze these documents and thus answer the research questions in a systematic fashion, a template analysis was conducted. Template analysis is a type of text analysis that uses a directed approach at analyzing text-based data (Hsieh and Shannon, 2005). Results of the template analysis are described in detail elsewhere (Kohon, 2015).

Sites and Sample

Based on the criteria discussed above, one neighborhood-level urban planning project was selected from each of the following cities: Portland, Oregon, U.S.; Copenhagen, Denmark; and Nagoya, Japan. Using snowball sampling, interviews (total $n$ $=22$ ) were conducted with community stakeholders involved in the planning project representing various perspectives at each site. Stakeholders included urban planners, community organization representatives, local business owners, marginalized 
populations, and community residents. Participant observation was conducted in each community at the street level, community events, and planning meetings.

\section{Data Collection}

Data were collected at each of the study sites between June 2013 and November 2013. One key stakeholder, or gatekeeper, from each project was contacted via email and invited to participate in an in-person interview. Each gatekeeper was asked for referral to other community stakeholders who have been involved in the planning process in the community and represent the various perspectives outlined above. Field notes were written immediately following each interview and observation. Gatekeepers were also asked for planning-related documents to be used to conduct the template analysis.

Interviews were conducted in English in Portland and Copenhagen. In Nagoya, the gatekeeper interview was conducted in English, and all other interviews were conducted in a combination of English and Japanese with the help of interpreters. All interviews were audio-recorded and transcribed. Interviews conducted in Japanese were translated and transcribed to English text by professional translators. Documents from Copenhagen were provided in English. Documents from Nagoya were provided in Japanese and translated to English for analysis.

Data Analysis 
Grounded theory methods were used to analyze qualitative data gathered from interviews and observations. These data were coded using Dedoose QDA software. Codes were developed from research questions (defining the social dimension), interview questions (what this place is about), and community concerns that emerged from the data (unwanted land uses). Initial coding, followed by focused coding was used to sort and categorize data based on the meaning behind participants' perspectives (Charmaz, 2006). The analysis phase consisted of an iterative process guided by a systematic method of asking analytic questions of the data. These questions included: 1 ) What's going on? (Lofland et al., 2006); 2) What is being said? What is not being said? What's missing? 3) Whose interests are being emphasized? Whose interests are being overlooked? Analytic memos were written throughout the data collection and analysis phase to keep track of emergent meanings, themes and theories.

\section{Results}

When planning for the social dimension of sustainability, participants of each community's planning process have collectively developed a vision for what that means to them. Commonly, their vision involves concepts of social inclusion and developing a sense of belonging in the community, such as in the case of the three neighborhoodscale projects in this study. This section will first provide a brief introduction to each community context and to their conceptualization of social sustainability. Finally, 
themes such as negotiating contested land uses, integration of the disenfranchised, and marginalization of the marginalized will be discussed.

\section{Visioning a Socially Sustainable Future}

Living Cully is a community planning project that seeks to reinterpret the idea of sustainability planning as an "anti-poverty strategy." Cully, a community on the margins of the city in northeast Portland, Oregon, is a neighborhood with a high concentration of low income and people of color residents, many of whom are Latino and Somali immigrants. On the other hand, there is a very active neighborhood association in Cully that is made up mostly of older Caucasian homeowners. Situated in a very prominent physical location in Cully lies a large sexually oriented business. There are several of these businesses in the neighborhood, yet this site has been at the center of much controversy due to its sordid reputation in the community and prominent location near a school and across the street from a multi-functional community center that includes play facilities for youth, a community center, housing, and a community health center. In this context of Portland, Oregon, sexually oriented businesses may legally be located on any property that is zoned for commercial use; the state constitution protects obscenity as free speech, which legally prohibits municipalities from regulating sexually oriented businesses differently than other types of businesses (McGrath, 2013). In this 
particular case, these lax land use regulations present challenges to the community's desires about the best use of the land on which the business in question sits.

As Living Cully is trying to shape their community for greater sustainability, they describe the social dimension of sustainability as follows:

I think it means environmental justice. And I think it means social cohesion so that the voices are represented and respected and there's access. It doesn't mean that everyone's going to be involved, but there's access for people to be involved, so there's an inclusivity to it that maybe you won't find everywhere. I would want to go see this in play and understand that: ok it's true, anyone could walk in these doors and find a place for themselves to have a moment at the table.

Living Cully's conceptualization of social sustainability highlights environmental justice, social cohesion, diverse representation, access to civic participation, and inclusivity.

The Sankt Kjelds Climate Quarter (SKCQ) project in the outer $\varnothing$ sterbro district of Copenhagen, Denmark is a joint climate adaptation project and urban renewal effort designed to give residents a "social lift." The "social lift" includes initiatives aimed at creating a sense of identity and belonging, as well as by upgrading historic apartment units from shared bathroom facilities to their own modern amenities. This neighborhood is a mixed-income community where one can find housing co-operatives, rental housing, a residential facility for Greenlanders ${ }^{1}$ who have severe chemical

\footnotetext{
${ }^{1}$ Greenland is a constituent country within the Kingdom of Denmark, also known as the Danish Realm. Though Greenland gained greater political independence through the establishment of "home rule" in 2009, supportive services from Denmark of various types continue to support Greenlanders with persistent need.
} 
dependency or mental health disorders, a nursing home for the elderly, and the relatively modest residence of Denmark's Prime Minister all within a short walk from one another. While the community is primarily made up of Caucasian-Danish residents, a recent influx of immigrants has changed the dynamic to include a small percentage of people of color, primarily of Middle Eastern descent. Though there are no sexually oriented businesses in SKCQ, the recent introduction of immigrants into the community has created some new complexities with which to contend. This stakeholder of the SKCQ project describes the initiative's conceptualizations of what social sustainability means to them as follows:

Our strongest focus in what we do culturally and socially is try to really create a stronger sense of identity for this area and create a sense of belonging...that people really feel at home where they are.... and then creating this, both the pride in the project, that they're actually seeing they're doing something for the safety of whole of Copenhagen once we have our next cloudburst but also using that to start a conversation about climate change and environmental behavior.

Here we can see their ideals of creating an identity, creating a sense of belonging, encouraging a feeling of home, and developing pride in the community project clearly articulated. This sentiment also reflects a strong partnership between social goals and environmental goals.

In the Chojamachi community in central Nagoya, Japan, the formerly thriving textile manufacturing and wholesale district has been experiencing economic, environmental and social decay. Over the last several decades, many owners of businesses and other residents of the community moved out to surrounding suburban 
areas. Global economic shifts in the textile industry have forced many businesses to close down permanently. Afraid they would not be able to rebuild successful businesses in the district, many landowners decided to demolish their buildings and pave over their land to create pay-to-park lots, thereby ensuring a more stable source of income. However, these fragmented vacant spaces have made conditions for rebuilding the social fabric of the community very difficult. Using machizukuri civic participation and community development practices (Murayama, 2007; Watanabe, 2007; Murayama and Sharifi, 2011; Koizumi, 2004), a community-based non-profit and some members of the business community have stepped up to regenerate the community with initiatives to entice new businesses, new residents, and community action. Stakeholders describe their vision for creating a socially sustainable community and those who would be invited to participate as follows:

We need to have a mentality of young, old, poor, rich, no problem. We want anyone and everyone to come... of course owners participate, but also people with no land holdings, residents, people who just work here and love the district, and young people, that are new to machizukuri and want to get involved here. So in a broad sense of the term, a diversity of people would be engaged, and it is this kind of community initiative to which we need to change.

This reflects openness to a broad range of new residents and participants in community engagement. However, community leaders are confronted with the challenges of immigrant groups buying properties and opening businesses in the district, and perhaps more troubling to stakeholders, Chojamachi's neighboring red-light district seems to be just on the edge of spilling over into the community. Chojamachi leaders are charged 
with addressing the challenges associated with both sexually oriented businesses and recent immigrants in their community.

\section{Negotiating Contested Land Uses}

These visions of idealism are met with complex challenges related to how to be inclusive and how communities can negotiate shared community space with land uses that are often contested. This stakeholder of Living Cully in Portland shares these conflicted feelings:

One of the things we're struggling with is actually how to recognize our mission of inclusion with businesses that aren't neighborhood serving. How do we include them? Because they are community members and how do we achieve a balance between not really having desirable business, but also respecting the rights to be there... Like strip clubs. How do we bring them to the table and get them to conduct business in a way that minimizes their impact without telling them that we just don't want you here.

As communities struggle with recognizing their values of inclusion, they find that inclusion of these businesses conflicts with the values of the majority of the community, at least those who have voiced their opinions. This conflict begs the question of who has the right to belong in the city. "There's a recognition that they have a right to be there. They're doing a business within the confines of the law, but they're not neighborhoodserving businesses." This tension between property rights and shared community values was shared among several stakeholders. 
Aside from conflicting with values that are commonly shared in the community, leaders are finding that their struggle to be inclusive, at times, conflicts with other community goals related to social sustainability, such as health, safety, public participation, and healthy child development. Community leaders are forced to weigh social inclusivity over concerns of nuisance and negative externalities of sexually oriented businesses, as indicated in this quote from one community stakeholder.

They bring in elements from outside the neighborhood that are not healthy. There was a shooting at the strip club a couple weeks ago. You know, and all of the other issues that go along with strip clubs. I think that, in general, most of the community would prefer they weren't doing business here. They're on Safe Routes to School's walking path. There are a large number of small children walking in front of those businesses... And what does that indicate to them? There's a school bus stop in front of the [adult business] across the street. There was a problem a couple of weeks ago with people from the [adult business] actually heckling the girls getting off the bus. And these are 10,11, 12 year old girls. So, that created a lot of tension.

When focusing in on the goal of healthy child development in the community, the concept of social inclusion is overshadowed and a trade-off must be made. This stakeholder explains that with regard to supporting their goal of supporting health child development, the community could be better off with a change to the use of a particular property that is currently a sexually oriented business.

Even if they were complying with all of the community's requests... There are a lot of other things that could be in that space that would be far more advantageous for the community. It is across the street from the single largest concentration of children under 5 in the area. What kind of message are you sending? 
The Chojamachi community in Nagoya lies just at the edge of a community that comes alive at night with adult entertainment. Since it is illegal for female hostess club workers to approach potential clients on the street, male employees approach salarymen as they walk through the district in an effort to gain their business at their nearby establishment. Women can be seen greeting customers as they arrive and exit these businesses. Chojamachi stakeholders lament of the negative effects these activities have on their plans for their community, "So, that is a problem for raising children. There are two such businesses [in Chojamachi] already. We want to prevent those from increasing." Here we see the intention to act out the community's vision of healthy child development, though it may be at the expense of excluding these types of land uses and social functions of society and their attendant challenges for the community.

\section{Integration of the Disenfranchised: Inclusion of immigrants and other marginalized groups}

Community planning project leaders also struggle with notions of social inclusion when it comes to groups of people who are not members of the dominant or powerholding population, such as immigrants, low-income residents, renters, people experiencing substance abuse or mental health problems, and older adults with mobility constraints. These communities have developed various methods for actively engaging marginalized groups in shared community life, though engagement in planning 
processes oftentimes presents more nuanced challenges. In the SKCQ project in Copenhagen, one stakeholder described a goal of actively working to integrate immigrants into the social fabric of the community:

I think the social things we do, like we have a person working here who is helping children of immigrants to get into sports clubs. It's very typical Danish to be a part of a sports clubs. They're called organization guides so they guide people into the organizations. Just helping the people who need to find out how it works to find the right places to activate their children.

In the Living Cully project, though they have challenges with local businesses that are not "community-serving businesses," organizers have actively reached out to include a diverse array of community members in sharing their visions for the community and participating in the planning process, as one described:

We all have very different backgrounds, but the unifying theme here is that we embrace our differences and that we have threads in common that are about being able to live a good life. And livability and prosperity and safety for our children. Those are things that we all have in common. It doesn't matter where we come from. I think that comes down to that visioning and missioning and getting that message out including those disenfranchised folks who are just blown away that we come down there and we want to talk. But they are members of the community. Even the strip club owners are members of the community and we are inviting them to a table. Doesn't have to be ideal.

Despite their efforts to integrate marginalized groups, challenges of ensuring diverse representation are all too common, particularly in leadership positions. Racial differences are particularly salient in Denmark, a country that has been relatively homogenously Caucasian until the recent influx of immigrants with dark skin have 
begun to call Copenhagen home. One stakeholder noted that in Copenhagen, every fourth person is from a different country, many of whom in Sankt Kjelds come from Turkey, Iraq and several other Middle Eastern countries. Yet, despite the prevalence of immigrants in the community, representation in the planning project remains a challenge. "Immigrants or second-generation immigrants are usually underrepresented. We might actually have immigrants but not dark immigrants." This stakeholder notes the difference social identifiers, such as immigrant status and dark skin, have on representativeness in community planning processes.

In the Living Cully community, a divide exists between representation in the neighborhood association and that of the non-profit community organizations serving Cully. While the neighborhood residents are predominantly low-income and people of color, the neighborhood association is made up of nearly all middle-income and Caucasian members. This stakeholder describes that dichotomy and their philosophy for changing the way people think about leadership in the community, with or without the neighborhood association.

Somali immigrants, low-income people of color immigrants, low-income people of color citizens, low-income whites. It's the majority. But if you look at leadership of the neighborhood association, there's one person of color. But then you have these strong institutions in the neighborhood now. We do have that leadership in our organizations. It really is about changing that dynamic of yes, those concerns are represented and there are not marginalized places. And this is what community economic development looks like in a neighborhood like Cully. That's part of the project. Exerting that to change the landscape and to 
change, you know, who when the city planners come and want to do stuff, who do they talk to.

The above statement reflects the community's desire to change their interface with local avenues for political power and influence. If the community leadership truly represents the demographics of the neighborhood through these strong communityserving institutions, it would enhance social inclusion and a sense of belonging among the various groups who are not represented by the membership of the neighborhood association. As the very active neighborhood association comes far from representing the demographics of the larger community, they have tried different strategies for involving a more representative crowd. Yet, they struggle with how to accommodate non-English speaking residents, as described by one participant:

We've bent over backwards trying to get the Spanish speaking community to be involved. We've hired interpreters for our meetings. We cannot get the Spanish community, the Latin community, involved. I talked to one Hispanic lady that could speak English and Spanish and she was saying that they don't like translators and they want the meeting all in Spanish which isn't going to happen (laughs). I think our board and our membership, I think we have equal representation from our neighborhood other than the non-English speaking. Ya know, we've tried; we just can't seem to find a solution.

Cultural competency plays an important role in social inclusion and cultivating a sense of belonging. In addition to creating competency to support cultural differences within leadership of community organizations, developing that capacity amongst the membership of these institutions and amongst residents of the community is equally important. It can be very challenging to be socially inclusive and nurture a sense of 
belonging when many participants of the process lack the skills to think outside the dominant monocultural perspective. Latinos in the community have indicated that neighborhood association meetings feel uninviting. The non-profit community organizations have responded by holding smaller scale community outreach events that are more accessible to diverse groups and by thinking about how to reach people where they're at rather than forcing them to adhere to dominant structures.

The Somali folks, they just aren't going to come to a meeting. So, that's a different question. You gotta go to them. Part of it is just making sure that you're scaling your outreach or that you're doing your outreach correctly. So, if you have a big meeting and say, "hey, everybody come to the meeting," it'll be a huge, well, people that are used to coming to those kinds of meetings. You're not going to get the Latino family. I've had Latinos tell me that they're afraid to go to the neighborhood association meetings, they don't feel comfortable with all those white people. You know, it's a problem. So, we tend to do more smaller type stuff, you know, at the end of the dead-end street by the trailer park. Stuff like that.

Undoubtedly, language and cultural barriers contribute to the difficulties of diverse representation. Reaching groups who are not "socially identifiable" remains a significant hurdle, as well, since those populations are unlikely to have a specific organization or leadership structure that represents their interests. One Living Cully stakeholder describes the work of a predominant community organization that supports the needs of Spanish-speaking residents, while other marginalized residents have little support, highlighting the need for targeted outreach.

They distribute all of their information in Spanish and they actively seek out Spanish speaking communities and so they really do a very effective job of 
creating a network of resources that are community based. In some ways they do a much better job of that than communities that aren't socially identifiable. Like there isn't a trailer parks $C D C$, right? There's no one representing the disenfranchised and marginalized folks that aren't socially identifiable. And that's a bit of a problem. There are a lot of really low-income people in this community that need someone to represent them. That community engagement component on our end comes in when we actually go door-to-door, and distribute information, and say this is what's happening, and how it's going to affect you, and where you can get more information. And that's a really large committed volunteer base.

Other initiatives that Living Cully organizations have initiated to engage diverse groups in the process and to ensure representative participation include intentionally selecting members of each group to represent the community's interests on each project and paying participants honoraria for their time. Leaders also provide childcare and hot food to participants and hold meetings at times that were most convenient to working parents to account for the many competing priorities they face. They've found this process to be very successful in ensuring representative participation and in building community trust.

The process of ensuring social inclusion in Sankt Kjelds involves bringing different social groups together to change preconceived notions about social identifiers, such a skin color. They've found that though their neighborhood school is of good quality and people seem to be reasonably happy with it, stigma and discrimination of nearby community members who have dark skin (compared to the traditional residents) have led many parents to seek out other options. 
Initially we thought we'd be kind of doing small events projects but now we're working with the school. It's Copenhagen's largest school and it's a pretty good school but it has had a bad reputation, which means that a lot of the resourceful people in the area put their children to private schools and the school actually has a large intake from pupils from Nørrebro, which is a more, um, has some more problems. There are a lot of rumors about the school. It's a really good school and the majority of the people who have their children there are really happy but one part of the goal is also to create some activities there to get parents to use the school and see the school before they have to decide which school to go to so they can see that it's actually a good school and wellfunctioning and the dark people that they might see aren't, uh, shouldn't scare them or anything.

SKCQ project leaders have expressed the goal of ending this socio-spatial segregation associated with the school and bringing members of the community together through inclusive activities. Many schools in Europe and the U.S. share this issue of how to incorporate racial and ethnic diversity, fairness, and inclusion with quality education when the dominant reference group perceives that education suffers when limited resources are used to include diverse groups.

\section{Marginalization of the marginalized - strategies for exclusion}

To achieve the planning goal of cultivating greater social sustainability, community leaders find they need to use strategies for active exclusion, a concept that may seem to run counter to this larger goal. Leaders, at times, face this challenge with conflicted feelings yet have found ways to adhere to the dominant values of the community. Whether explicit exclusion or implicit exclusion through perceptions and 
assumptions, various routes lead to excluding certain marginalized or stigmatized groups from civic participation or merely from occupying physical community space.

\section{Explicit exclusion}

To limit the presence of sexually oriented businesses, changes to city zoning ordinances are a common solution, as this Chojamachi representative explains. "So we were trying to create that kind of rule in the local law through our planning to prevent that land use. We were able to get a lot of agreement about preventing the [red-light district] and prostitution business." After a long process of trying to work with the owners of the most prominent sexually oriented business in Cully with little success, community leaders worked to have land use zoning changes implemented on this property that was already operating as such a business. This change would put the property into a zoning category that would essentially raise the value of the land, creating a significant incentive for the owners to sell. Their strategy involved labeling and messaging about "community-serving businesses" to make a clear statement about what kind of identity the community wanted to cultivate.

What we were able to do, through a lot of public participation was to re-zone. The property would be worth a lot more money, which you wouldn't want to reward them, but what has now been done is that the property will be sold because the property is worth more money and it will be rebuilt. And it won't be a strip club anymore after the strip club is gone.

Achieving success in this process, after the property went up for sale, the community began a campaign to raise funds to purchase the property in an effort intended to 
displace any other potentially undesirable land uses and regain control over the prominent neighborhood space.

Because Chojamachi's population has declined, the municipal government has talked about the possibility of closing the local elementary school. Community leaders in Chojamachi are vying to keep the school open in an effort to keep sexually oriented businesses from flooding into the neighborhood. Since there is a restriction on how close in proximity these types of businesses can locate from a school, this strategy could help them to actively exclude these businesses from Chojamachi.

Brothels are being excluded from this area. This is because there is an elementary school in the area. When you have these around, it is good for the environment. What I think and what everyone thinks is most important is that if the elementary school closes, the environment will degrade. Actually the rules say you can't have them [brothels], and that they are here is an issue. It is an issue of protecting the elementary school.

Other efforts to exclude relate to outsider groups, such as Chinese business owners, who are not seen as viable representatives of the community and, as such, Japanese community members are explicit about not including them in community planning activities in Chojamachi.

There are certain groups of people who are kind of considered as outsiders. Many Chinese investors are buying properties in Japan. Even in [Chojamachi], there are several properties that are already bought by Chinese people. Even if there are some Chinese investors or property owners or restaurant owners, the community, Japanese people in the community would not say that we want to involve them in our activities. They're just, they're doing their things and as long as they don't make any trouble, it's ok. 
Since they are actively trying to attract new residents to move into Chojamachi and reenliven the social fabric of the community, they have developed several ideas for realizing this goal. They are very clear about what kind of community they would like and whom they would like to exclude as they plan for moving forward.

One idea that comes to mind is childcare space. There is one facility but right next to that is the red-light district. The childcare facility is for the people working just next door in adult entertainment. So rather than that, we need more childcare for shokujuukinzai [work-live-neighborhoods].

This sentiment demonstrates a clear conceptual distinction between community insiders and outsiders and how socio-spatial organization follows this distinction.

\section{Implicit exclusion}

Other methods of social exclusion were more subtle. Implicit exclusion occurred when perceptions or assumptions clouded efforts to include certain groups in planning activities. In Living Cully, assumptions about Somali and Latino residents create barriers to engaging with them. Many of these perceptions and assumptions are unconfirmed, yet they continue to guide interactions with these groups.

Hispanic speaking and Somalia speaking have cultural problems and I'm not sure what they are. Somalia people, number one, we meet at a church. What I've heard is that the Somalia's will not go to a meeting that's held in a church, but we have no public meeting space that will hold the size of group we have... The Somalia men don't want their women out at night and trying to get them to come to any kind of meeting is very difficult. The Hispanic community has been really hard also and I don't know that they have a barrier as far as male/female, letting the females come out at night or not, but we have not been able to get any Hispanics involved, period, none. 
In Chojamachi, a common perception is that yakuza, the Japanese mafia, run the majority of sexually oriented businesses in Japan. Community leaders hesitate to engage with these business owners out of fear that they'll get entangled with yakuza members. Furthermore, implicit exclusion also occurs in assuming that certain types of people, such as sexually oriented businesses would not want to be involved in planning activities, even if they were invited.

There are residents who are working in the adult entertainment district east of [Chojamachi] and their lifestyle is totally different and of course, I mean, they are not interested in becoming involved in the community activities anyways but there are lots of population of that type.

This implicit exclusion is based on preconceived ideas and assumptions about who would want to be involved. Through this process, community leaders implicitly make decisions about who should be at the table in planning for the future of the community.

\section{Discussion}

This study finds that in planning for social sustainability in neighborhood-scale planning projects, community leaders are forced to make choices and trade-offs about which conceptual goals take precedence, particularly when it comes to sexually oriented businesses and other marginalized groups. Communities struggle over how to negotiate contested land uses, how to be socially inclusive and when to use strategies to actively exclude members of the community. At times, these communities are simultaneously dancing between actively including marginalized folks and actively excluding them. When, idealistically, everyone should have the right to the city, where does a 
community draw the lines for achieving social inclusion? Who decides who should be included? When cultivating a sense of belonging in a neighborhood, who should feel that they belong?

To answer these questions, communities are forced to confront their ideals about the future of the community and address concerns related to capacity building, as well as make decisions about which goals are more important at any given time. Planning for social inclusion requires changes to long-standing community structures and institutional processes. It also often requires shifting community members' longheld dominant monocultural views toward multi-cultural competency. When the question of who decides who should be included is asked, one would hope that those at the table represent the diverse interests of the community or at least that leaders interact with the diverse groups in the community often enough and with enough cultural competency to represent their interests and effectively preserve spatial and social justice. De Souza Briggs (2008) stresses the importance of the role of planners as culturally competent facilitators of inclusive community decision-making, particularly in high-poverty and culturally diverse communities. Findings about representation among community members indicate that many community representatives in powerful decision-making positions, though not trained as culturally competent planners, are essentially making decisions about who can be involved, in what capacity individuals or groups can be involved, and ultimately what social sustainability means for the community. 
These communities have illustrated that building social sustainability on the ground requires negotiating the concept of inclusion. NIMBY attitudes towards LULUs are quite difficult to address. Campbell (1996) describes this in his critique of the three pillars model of sustainability as the "property conflict," which arises from "competing claims on and uses of property," as it falls between economic development and equity and social justice on the planner's triangle of fundamental priorities and resulting conflicts. Diverse interests in land uses, groups of people and occupations exist in cities. If sexually oriented businesses do not exist in one neighborhood, they will most likely exist in another. The challenge of inclusivity, however, particularly of these controversial types of businesses, comes with risks and rewards for different segments of the population. Perhaps, in the long-term view, a socially sustainable society will find ways to minimize the conditions that give rise to the need to have these sexually oriented business or other LULUs. In the meantime, communities must contend with these contested spaces.

Furthermore, sexually oriented businesses can be seen as an identifier for communities. By excluding sexually oriented businesses from their community, Cully and Chojamachi, hope to cease being identified as marginal urban locations or marginalized communities. However, a delicate balance exists between marginalization and gentrification (Hubbard, 2008; Papayanis, 2000). Godschalk (2004) identifies the gentrification value conflict, which arises amidst tensions between social equity and livability within the context of sustainable development. Living Cully, in particular, has 
been actively working to prevent negative effects of potential gentrification. The transition of the prominent sexually oriented business in Cully to another type of land use could shed their reputation as 'marginalized by association' and usher in the forces of gentrification, which brings with it other challenges related to social sustainability, such as affordability and accessibility. It can be easy to forget that these complex urban problems are inextricably interconnected and require consideration of cause and effect within these dynamic systems.

The research raises many questions that have yet to be addressed by the social sustainability literature. What are the limits of inclusion? Should the gate be wide-open to include every possible community actor in neighborhood space and in institutional processes? Or should the gate be more selective? If so, who are the appropriate gatekeepers? Whose judgment is right or best? Are there legitimate activities or lifestyles that should be considered? In socially sustainable urban communities, what does inclusion really mean? At what scale should decisions be made? In the case of NIMBY attitudes towards LULUs or exclusionary attitudes towards newcomers, should the city mediate to ensure inclusion, enforce rules, and enforce codes? Should the city be involved in helping communities to take action to remove LULUs from the community? What does social sustainability mean in this context? While the literature continues to grapple with defining and operationalizing the concept of social sustainability, communities are attempting to plan for and navigate myriad questions and conflicts related to the reality of a future ideal of social sustainability. 


\section{Limitations}

This study is potentially limited by social desirability bias, in that interviewees may be inclined to speak with political correctness with regard to feelings about sexually oriented businesses and immigrants and to share their perspectives in a way that they think the author would like to hear them. At times, given these topics, being a female interviewer seemed to present a challenge for male interviewees to be able to speak candidly about sexually oriented businesses in the community. Cultural differences in the case of Sankt Kjelds and Chojamachi may have also effected how comfortable they felt in speaking with the author about such topics.

Each of these projects is ongoing. Throughout planning processes much can be learned, managed and solved. While the author interviewed these participants at one point in time, their perspectives or tactics in managing these challenges may have changed in any number of directions. Follow up research would provide more depth in understanding how these challenges and trade-offs were managed over time.

\section{Conclusion}

This study explores the complex dialectic between social sustainability theory and praxis in an urban planning context. Findings from this research are novel in that they provide an empirical basis for understanding the inherent subjectivities in planning for social sustainability at the neighborhood-scale. The complexities of social inclusion 
and creating a sense of belonging discussed here help to support a more nuanced conceptualization of the theoretical components of social sustainability. While scholars have identified social inclusion and nurturing a sense of belonging as important components of creating socially sustainable communities, in urban planning practice trade-offs are often required to achieve these occasionally conflicting goals. Furthermore, this research raises many questions that can be answered by future research to build social sustainability theory about the limits of inclusion, at what scale decisions should be made, and in understanding the effects of power relations in urban communities on planning for social sustainability at the neighborhood-scale.

\section{References}

Arnstein, S. R. (1969) Ladder of citizen participation, Journal of American Institute of Planners, 35(4), pp. 216-224.

Bernard, H.R. and Ryan, G.W. (2010). Analyzing Qualitative Data: Systematic Approaches. Sage Publications: Thousand Oaks, CA.

Campbell, S. (1996). Green cities, growing cities, just cities?: Urban planning and the contradictions of sustainable development. Journal of the American Planning Association, 62(3), 296-312. doi:10.1080/01944369608975696. 
Charmaz, K. (2006). Constructing grounded theory: A practical guide through qualitative analysis. Thousand Oaks, CA: Sage Publications.

Day, D. (1997). Citizen Participation in the Planning Process: An essentially contested concept? Journal of Planning Literature, 11(3), p. 421-433.

Dempsey, N., Bramley, G., Power, S., and Brown, C. (2011). The social dimension of sustainable development: Defining urban social sustainability. Sustainable Development, 19, 289-300.

De Souza Briggs, Xavier. (2008). Doing democracy up-close: culture, power, and communication in community planning. In DeFilippis, J. and Saegert, S. (eds.), The Community Development Reader, Routledge; New York, NY.

Fincher, R. and Iveson, K. (2008). Planning and Diversity in the City: Redistribution, recognition and encounter. Palgrave MacMillan: New York, NY.

Flyvbjerg, Bent. (2001). Making Social Science Matter: Why social inquiry fails and how it can succeed again. Cambridge, UK: Cambridge University Press.

Godschalk, (2004). Land use planning challenges: coping with conflicts in visions of sustainable development and livable communities. Journal of the American Planning Association, 70 (1) (2004), pp. 5-13.

Harvey, D. (2003), The right to the city. International Journal of Urban and Regional Research, 27,939-941. doi: 10.1111/j.0309-1317.2003.00492.x. 
Hubbard, P., Boydell, S., Crofts, P., Prior, J., and Searle, G. (2013). Noxious neighbors? Interrogating the impacts of sex premises in residential areas. Environment and Planning A, 45, 1-16.

Hubbard, P. J., Matthews, R., Scoular, J., \& Agustín, L. (2008). Away from prying eyes? The urban geographies of 'adult entertainment'. Progress in Human Geography, 32(3), 363-381. doi: 10.1177/0309132508089095.

Hsieh, H. and Shannon, S. (2005). Three approaches to qualitative content analysis. Qualitative Health Research, 15, 1277-1288.

Kohon, J. (2015). Interpretations of the Social Dimension of Sustainability in Urban Regeneration Practice: Application of a Social Determinants of Health Lens. Unpublished manuscript.

Koizumi, H. (2004). Empowerment in the Japanese planning context. In Sorensen, A., Marcotullio, P. and Grant, J. Towards Sustainable Cities: East Asian, North American and European Perspectives on Managing Urban Regions. Ashgate: Hampshire, England.

Krieger, N. (1999). Embodying inequality: A review of concepts, measures, and methods for studying health consequences of discrimination. International Journal of Health Services: Planning, Administration, Evaluation, 29, 295-352. 
Lefebvre, H. (1991). The production of space (D. Nicholson-Smith, Trans.). Cambridge, MA: Blackwell.

Levine, P., Fung, A., and Gastil, J. (2005). Future directions for public deliberation. In Gastil, J. and Levine, P. (eds.) The Deliberative Democracy Handbook. San Francisco, CA: Jossey-Bass.

Levitas, R., Pantazis, C., Fahmy, E., Gordon, D., Lloyd, E., \& Patsios, D. (2007). The multidimensional analysis of social exclusion. Bristol: Department of Sociology and School for Social Policy, University of Bristol.

Lofland, J., Snow, D., Anderson, L., \& Lofland, L. (2006). Analyzing social settings. $4^{\text {th }}$ ed. Belmont, CA: Wadsworth Press.

McGrath, Moriah McSharry, "Neighboring in Strip City: A Situational Analysis of Strip Clubs, Land Use Conflict, and Occupational Health in Portland, Oregon" (2013). Dissertations and Theses. Paper 1046.

Murayama, A. (2007). Civic Movements for Sustainable Urban Regeneration: Downtown Fukaya City, Saitama prefecture. In Sorenson, A. and Funck, C. (eds.) Living Cities in Japan. New York, NY: Routledge.

Murayama, A. \& Sharifi, A. (2011). Low-Carbon Strategy and Community Development in Nagoya, Japan: Case of Nishiki 2 District, a Fabric Warehouse District in 
Transition. Conference Proceedings, EcoDistricts Summit, October 27, 2011, Portland, Oregon.

Norton, B. and Hannon, B. (2004). Democracy and sense of place values in environmental policy. In Norton, B. (Ed.) Searching for Sustainability: Interdisciplinary Essays in the Philosophy of Conservation Biology. Cambridge University Press: Cambridge, U.K.

Papayanis, M. (2000). Sex and the revanchist city: zoning out pornography in New York. Environment and Planning D: Society and Space, 18, 341-54.

Popper, F. J. (1981). Siting LULU's. Planning, 47(4), 12-15.

Taket, A., Crisp, B., Graham, M., Hanna, L., and Goldingay, S. (2014). Scoping social inclusion practice. In Taket, A., Crisp, B., Graham, M., Hanna, L., Goldingay, S., and Wilson, L. (Eds). Practising Social Inclusion. Routledge: London \& New York.

Vallance, S., Perkins, H. C., \& Dixon, J. E. (2011). What is social sustainability? A clarification of concepts. Geoforum, 42(3), 342-348.

Watanabe, S.J. (2007). Toshi Keikaku vs. Machizukuri : Emerging paradigm of civil society in Japan, 1950-1980. In Sorenson, A. and Funck, C. (2007). Living Cities in Japan : Citizens' Movements, Machizukuri and Local Environments. Nissan Institute/Routledge Japanese Studies Series : New York, NY. 
Yin, R. (2014). Case Study Research: Design and Methods. Fifth edition. Thousand Oaks, CA: Sage Publications, Inc. 


\section{Conclusion}

This research examines the concept of urban social sustainability at the neighborhood-scale through three avenues. First, in Chapter One, conceptualizations of the meaning of social sustainability are described in the three different projects. These three communities are framing social sustainability in terms that match key components of social determinants of health (SDH). Each community differentially emphasizes structural and contextual determinants of health according to the needs and situational context of the particular community. Next, Chapter Two explores the challenges and facilitating factors associated with political economy in the three different national and local contexts. National political economic context dictates, to a large degree, the level and extent of social factors on which that these communities must focus planning efforts in order to work toward social sustainability. This analysis elucidates inherent conflicts between national, municipal and neighborhood-scales in planning for social sustainability. Finally, Chapter Three takes to task the theoretical notions of social inclusion and nurturing a sense of belonging, considered to be integral components of social sustainability, as they are applied to urban planning practice at the neighborhoodscale. This analysis finds that these theoretical ideals are contested when it comes to the complex nuances of including marginalized groups such as sexually oriented businesses and immigrants into community space, social organization and planning practice. 


\section{Dialectic between Theory and Practice}

This project represents a dialectic between theory and practice. As such, findings from this research present significant empirical contributions to academic literature and to urban community planning practice. As discussed in the introduction to this study, social sustainability is described in recent literature as a "concept in chaos" (Vallance, Perkins, and Dixon, 2011). This research contributes to this literature in several important ways. Findings inform social sustainability theory from current, on-theground planning practice by describing what communities in different contexts are doing to plan for social sustainability. Gaining a greater understanding of simply what it is that communities consider to be important principles of social sustainability in planning practice informs our theoretical understanding of this contested concept. This study also bridges theory and practice by exploring the achievements and challenges communities face in grappling with this "concept in chaos." Communities struggle with simply trying to understand what it means to work toward social sustainability and in designing plans to reach those often intangible goals. When our theoretical understanding of this concept is in chaos, how are communities to be expected to know how to navigate this terrain on the ground?

\section{Inform Practice}

To answer this question, this research connects the SDH framework to the theory and practice of social sustainability in an urban context to both inform the 
literature as to a structure for social sustainability principles and to arm communities with tools to facilitate their planning efforts. With regard to practice, these communities are experiencing the challenges of finding ways to frame the social dimension in such a way to positively affect the social conditions of their neighborhood. Yet, what they have come up with maps onto the principles of the SDH framework. To prevent other communities from struggling through this process, this framework addresses the challenges communities face in framing the issue and provides them with action areas within which they can focus their efforts and, at times, limited resources. As such, the SDH provides a framework or tool with which communities, government officials and policymakers can plan for social sustainability.

\section{Inform Theory}

With regard to theory, the SDH framework gives structure to the conceptual chaos of social sustainability (Vallance, Perkins, and Dixon, 2011). While scholars continue to debate the components or principles of social sustainability, communities, such as those explored in this study, are already framing the concept in terms of SDH and implementing these ideas on a neighborhood-scale. This research informs theory from empirical study of what is happening in practice and connects the interdisciplinary conceptual framework of SDH to social sustainability theory. In this case, empirical knowledge from practice informs theoretical knowledge. 


\section{Social Determinants of Health Framework}

Using the SDH framework places a strong emphasis on social justice and the reduction of social inequities in health and social well-being. Reducing inequities, even starting just with the neighborhood-scale, will thereby reduce inequities in health outcomes and benefit the whole population in a society (Wilkinson, 1996). Many scholars have highlighted this desire to include social justice in the sustainability paradigm (Agyeman and Evans, 2003; Dujon, 2009). This SDH framework approach ensures alignment with principles of "just sustainabilities" (Agyeman, 2013, p. 22-25), particularly with regard to creating equitable conditions for meeting the needs of both present and future generations.

\section{Context Matters: Structural and Contextual Determinants}

One such way that this research informs theory is that it exemplifies some ways in which planning for social sustainability is context specific (Lehtonen, 2004) and introduces the structural and contextual components of context on which to emphasize. Chapter One delves into these two main types of social determinants of health: structural and contextual. Structural determinants relate to the structure of our society as described in Chapter Two as those elements most directly impacted by political economic context. Structural determinants include income, wealth, education, occupation, social class, gender, human rights, race, ethnicity, equity, and social justice. Generally speaking, a higher level of support by national and local context on these 
structural social issues, as is common in advanced social welfare states such as

Denmark, translates to a focus on more contextual determinants, which are arguably more amenable to management at the neighborhood-scale than structural determinants. This work takes social sustainability theory beyond simply stating that the concept is context-specific and provides a view into the mechanisms behind the layers of context so that communities may focus in on those factors that require interventions to work toward social sustainability.

\section{Scale: Interactions Between Neighborhood-Scale and Political Economy}

This research introduces the neighborhood-scale to thinking on social sustainability. Neighborhoods are important social units that have meaningful consequences for health and social well-being. Different built and social environments of neighborhoods have been shown to confer benefits and deficits on individuals and social groups (Kawachi and Berkman, 2003; Drewnowski, Rehm, and Solet, 2010). Neighborhood-scale planning offers great opportunities to target small-scale interventions to address community-specific social needs. However, this scale also presents myriad challenges. Many persistent urban social problems are rooted at a much broader societal scale. Therefore, targeting interventions at the neighborhoodscale may feel like somewhat of a Band-Aid solution on a severed limb-scale problem. Therefore, community stakeholders are tasked with navigating relationships with those in positions of power at scales outside of the neighborhood, such as the city government and national political economy, and grappling with how to negotiate 
seemingly intractable urban social problems that stem from larger societal ills and inequities. Few studies discuss the influence of political economy in relation to planning for social sustainability and no other studies discuss political economy in relation to planning for social sustainability at the urban neighborhood-scale. This research introduces the nuances of planning for social sustainability at the neighborhood-scale within in "unjust economic systems" (Agyeman and Evans, 2003, p. 48) as compared to a social welfare context, which faces different types of challenges.

\section{Informing Sustainability from Planning Practice}

This neighborhood-scale focus also informs the more broad sustainability literature on the ways in which the social dimension is contested at this scale. The social dimension of sustainability has been the most under-theorized and under-researched dimension of sustainability and little work has been done to understand the nuanced needs of planning for this underdeveloped dimension on a neighborhood-scale. This research highlights that communities are trying to plan for social sustainability without much guidance from currently available sustainability planning methods, which focus primarily on the environmental dimension. This work underscores that communities would benefit from practical support, such as the SDH framework, to aid in planning for social sustainability at the neighborhood-scale. Several interview participants indicated that they have been struggling to find some guidance to figure out what they can do to support social sustainability. Though much of the very clear guidance for sustainability initiatives has focused primarily on navigating complex environmental systems such as 
Green Building Standards, these complex social systems require some attention, as well, within the realm of sustainability planning practice. This research offers a step forward to this regard.

\section{Ground Truthing of Social Sustainability Ideals}

Chapter 3 contributes to the literature by interrogating the dynamics of implementing theoretical ideals of social sustainability, such as social inclusion and nurturing a sense of belonging, at the neighborhood-scale. This work represents a ground truthing of theoretical notions of social sustainability. Results indicate that there are inherent trade-offs that need to be considered between the component ideals of social sustainability to get to a shared community vision of social sustainability. Concerns raised include whose version of social sustainability is correct, who's included in the process of deciding, and who's interests will be supported in the "shared" community vision. This analysis raises many questions that have yet to be answered by the academic community, such as: what are the limits to social inclusion? And what does social inclusion really mean? Should social inclusion be open and unchallenged or should limits or structures be put on? Are there legitimate activities or lifestyles that should not be included? Who decides? Who has the power and who does not? What can happen when those in the neighborhood who are most involved, who have the most power to make decisions, are not necessarily trained at cultural competence? What are the things that take care of people and what things do not? Ideally, will a socially sustainable society find ways to minimize the conditions that give rise to the 
need to have sexually oriented businesses in urban communities? When we're just not quite there yet, in the meantime, how do we negotiate these contested spaces in the urban social fabric? Planning for social sustainability cannot only be conducted at the grassroots level because of the limits to social inclusion, such as NIMBY attitudes towards LULUs, described in Chapter 3 and the limits of political economy at the neighborhood-scale described in Chapter 2. As such, what is the role of the city and higher scales of governance in mediating these discrepancies? These and other questions need to be weighed in planning for social sustainability at the neighborhoodscale.

\section{Future Research}

Academic research on the social dimension of sustainability is in a very early stage. In addition to addressing the questions raised herein, there remains much to understand and contemplate to make progress in this important dimension of sustainability. This section will highlight five key areas in which future research on the social dimension of sustainability could benefit from further investigation: SDH framework, contexts, limits and trade-offs, connections between other dimensions, and co-benefits.

While others have examined the use of an SDH framework with concepts of social sustainability (Baugh Littlejohns and Smith, 2014; Carlson and Everett, 2013), there is much work to be done in this area to better connect this conceptual framework 
with proven interventions within the realm of social sustainability planning at different scales. Fortunately, the field of public health has been working with this interdisciplinary framework and corollary interventions have been developed and tested at various scales. Social sustainability theory and practice would benefit from exploration into these interventions to identify appropriate actions to take as a step forward in urban planning practice.

As this research demonstrates, there is much to be understood about the ways in which context influences notions of social sustainability. The academic literature in this area would benefit from more case studies and other research methods that delve into additional contexts and scales. The projects discussed in this research are all situated in a developed or first world context. However, much can be learned about how factors associated with developing world mega-city contexts, for example, such as high-poverty levels, rapid urbanization, overpopulation, and informal urban settlements, impact planning for social sustainability. Exploring context at different scales of social sustainability planning, such as the municipal, regional, state or perhaps even federal level, would contribute important layers to social sustainability literature and practice.

As discussed earlier, scholarship on social sustainability would benefit tremendously by further exploration into the limits of conceptual notions within the social sustainability discourse and a deeper understanding of the role of trade-offs between separate ideals, such as Chapter 3 explores. Interrogating the limits of notions such as social inclusion and a sense of belonging, in addition to others that have yet to 
be explored, would move understanding in this area forward. The limits of scale, explored in Chapter 2, to address larger social issues connected to societal structure is another area that deserves more attention from empirical work.

One of the key areas for future research is in expounding the connections between other dimensions within the sustainability paradigm. In what ways do efforts toward addressing social dimensions affect the environmental and economic dimensions? More research is needed in drawing stronger connections between human health and the individual behaviors and intentional actions that affect changes to environmental perspectives on sustainability. Connections between social and environmental dimensions also evoke concepts of environmental justice and climate justice. The SDH framework represents connections with other dimensions through socioeconomics and built environment. More work is needed to understand the nuances of two different conceptualizations of connections between the social and environmental dimensions. One such conceptualization is that of understanding the nuances of social environments, such as those constituted by neighborhoods, families, peers, schools, workplaces, and even community planning processes. Another conceptualization is the ways in which our community social systems impact the physical or natural environment. Certainly, much research has been done on travel behaviors, waste management, and other environmental side effects of the ways in which our social systems are oriented. However, future research could take on 
questions related to the impact of social inequity on the physical or natural environment.

Finally, we know that efforts to work toward environmental sustainability have positive co-benefits for public health and social sustainability. For example, climate adaptation planning can support efforts to reduce famine, increase physical activity, and promote healthy environmental conditions. However, future research on the ways in which planning for social sustainability confers co-benefits on economic and environmental dimensions could support efforts to frame the importance of the social dimension and potentially build stronger connections for practitioners to understand the importance of working toward social sustainability goals. 


\section{References}

Agyeman, J. (2013). Introducing Just Sustainabilities: Policy, Planning, and Practice. Zed Books; NY, NY.

Agyeman, J., \& Evans, T. (2003). Toward just sustainability in urban communities:

Building equity rights with sustainable solutions. The ANNALS of the American Academy of Political and Social Science, 590(1), 35 -53. doi:10.1177/0002716203256565.

Arnstein, S. R. (1969) Ladder of citizen participation, Journal of American Institute of Planners, 35(4), pp. 216-224.

Baugh Littlejohns, L. \& Smith, N. (2014). Building bridges between health promotion and social sustainability: an analysis of municipal policies in Western Canada. Local Environment, 19, 4, 449-468.

Bernard, H.R. and Ryan, G.W. (2010). Analyzing Qualitative Data: Systematic Approaches. Sage Publications: Thousand Oaks, CA.

Boswell, M., Greave, A., and Seale, T. (2012). Local climate action planning. Washington, D.C.: Island Press.

Bryant, T. (2010) Politics, public policy, and health inequalities. In Bryant, T., Raphael, D., and Rioux, M. (Eds.). Staying Alive: Critical Perspectives on Health, Illness, and Health Care. 2nd Edition. Canadian Scholars' Press Inc.: Toronto, CA. 
Campbell, S. (1996). Green cities, growing cities, just cities?: Urban planning and the contradictions of sustainable development. Journal of the American Planning Association, 62(3), 296-312. doi:10.1080/01944369608975696.

Carlson, M. and Everett, M. (2013). Social Sustainability and the Social Determinants of Health: Understanding the Connection. In: Social Sustainability: A Multilevel Approach to Social Inclusion. Ed. Veronica Dujon, Jesse Dillard, Eileen M. Brennan. New York, NY: Routledge.

Charmaz, K. (2006). Constructing grounded theory: A practical guide through qualitative analysis. Thousand Oaks, CA: Sage Publications.

Coburn, D. (2000). Income inequality, social cohesion and the health status of populations: the role of neo-liberalism. Social Science \& Medicine, 51(1), 135146. doi.org/10.1016/S0277-9536(99)00445-1.

Colantonio, A. and Dixon, T. (2009). Measuring socially sustainable urban regeneration in Europe. Oxford Institute for Sustainable Development, pp. 1-129.

Crabtree, B. and Miller, W. (1992). Doing Qualitative Research. Newbury Park, CA: Sage Publications, Inc.

Davidson, M. (2010). Sustainability as ideological praxis: The acting out of planning's master-signifier. City, 14 (4), p. 390-405. 
Day, D. (1997). Citizen Participation in the Planning Process: An essentially contested concept? Journal of Planning Literature, 11(3), p. 421-433.

Dempsey, N., Bramley, G., Power, S., and Brown, C. (2011). The social dimension of sustainable development: Defining urban social sustainability. Sustainable Development, 19, 289-300.

De Souza Briggs, Xavier. (2008). Doing democracy up-close: culture, power, and communication in community planning. In DeFilippis, J. and Saegert, S. (eds.), The Community Development Reader, Routledge; New York, NY.

Dillard, J., Dujon, V., and King, M. (2009). Understanding the Social Dimension of Sustainability. New York: Routledge.

Drewnowski, A., Rehm, C., and Solet, D. (2010). Disparities in obesity rates: Analysis by ZIP code area. Social Science \& Medicine, 65(12), p. 2458-2463.

Dujon, V. (2009). In the Absence of Affluence: The Struggle for Social Sustainability in the Third World. In Understanding the Social Dimension of Sustainability. New York: Routledge.

Fincher, R. and Iveson, K. (2008). Planning and Diversity in the City: Redistribution, recognition and encounter. Palgrave MacMillan: New York, NY.

Flyvbjerg, Bent. (2001). Making Social Science Matter: Why social inquiry fails and how it can succeed again. Cambridge, UK: Cambridge University Press. 
Fullilove, M. T. (2004). Root Shock: How tearing up city neighborhoods hurts America, and what we can do about it. New York: One World Books.

Gehl, J. (2010). Cities for People. Washington, D.C.: Island Press.

Godschalk, (2004). Land use planning challenges: coping with conflicts in visions of sustainable development and livable communities. Journal of the American Planning Association, 70 (1) (2004), pp. 5-13.

Hallsmith, G. (2003). The Key to Sustainable Cities: Meeting Human Needs, Transforming Community Systems. New Society Publishers; Gabriola Island, BC.

Harvey, D. (2003), The right to the city. International Journal of Urban and Regional Research, 27,939-941. doi: 10.1111/j.0309-1317.2003.00492.x.

Helliwell, J., Layard, R. and Sachs, J. (2013). World Happiness Report 2013. United Nations.

Heymann, J., Earle, A., and Hayes, J. (2004). The Work, Family and Equity Index: Where Does the United States Stand Globally? Institute for Health and Social Policy. McGill University.

Holden, M. (2012). Urban Policy Engagement with Social Sustainability in Metro Vancouver. Urban Studies, 49(3), 527 -542. doi:10.1177/0042098011403015.

Hsieh, H. and Shannon, S. (2005). Three approaches to qualitative content analysis. Qualitative Health Research, 15, 1277-1288. 
Hubbard, P., Boydell, S., Crofts, P., Prior, J., and Searle, G. (2013). Noxious neighbors? Interrogating the impacts of sex premises in residential areas. Environment and Planning A, 45, 1-16.

Hubbard, P. J., Matthews, R., Scoular, J., \& Agustín, L. (2008). Away from prying eyes? The urban geographies of 'adult entertainment'. Progress in Human Geography, 32(3), 363-381. doi: 10.1177/0309132508089095.

Jacobs, J. (1961). The death and life of great American cities. New York: Random House.

Jackson, K. (1985). Crabgrass Frontier. New York: Oxford University Press.

Kawachi, I. and Berkman, L. (2003). Neighborhoods and Health. New York: Oxford University Press.

Kohon, J. (2015). Interpretations of the Social Dimension of Sustainability in Urban Regeneration Practice: Application of a Social Determinants of Health Lens. Unpublished manuscript.

Koizumi, H. (2004). Empowerment in the Japanese planning context. In Sorensen, A., Marcotullio, P. and Grant, J. Towards Sustainable Cities: East Asian, North American and European Perspectives on Managing Urban Regions. Ashgate: Hampshire, England. 
Krieger, N. (1999). Embodying inequality: A review of concepts, measures, and methods for studying health consequences of discrimination. International Journal of Health Services: Planning, Administration, Evaluation, 29, 295-352.

Lefebvre, H. (1991). The production of space (D. Nicholson-Smith, Trans.). Cambridge, MA: Blackwell.

Lehtonen, M. (2004). The environmental-social interface of sustainable development: capabilities, social capital, institutions. Ecological Economics, 49(2), 199-214. doi:10.1016/j.ecolecon.2004.03.019.

Levine, P., Fung, A., and Gastil, J. (2005). Future directions for public deliberation. In Gastil, J. and Levine, P. (eds.) The Deliberative Democracy Handbook. San Francisco, CA: Jossey-Bass.

Levitas, R., Pantazis, C., Fahmy, E., Gordon, D., Lloyd, E., \& Patsios, D. (2007). The multidimensional analysis of social exclusion. Bristol: Department of Sociology and School for Social Policy, University of Bristol.

Littig, B., \& GrieBler, E. (2005). Social sustainability: a catchword between political pragmatism and social theory. International Journal of Sustainable Development, 8, 65-79. 
Lofland, J., Snow, D., Anderson, L., \& Lofland, L. (2006). Analyzing social settings. $4^{\text {th }}$ ed. Belmont, CA: Wadsworth Press.

Living Cully Partner Organizations. (2013). Living Cully: A Cully Ecodistrict. Fact sheet from Living Cully Partner Organizations.

Lubell, J., Crain, R., and Cohen, R. (2007). Framing the issues: The positive impacts of affordable housing on health. Center for Housing Policy.

Massey, D. \& Denton, N. (1993). American Apartheid: Segregation and the Making of the Underclass. Cambridge, MA.: Harvard University Press.

McGrath, Moriah McSharry, "Neighboring in Strip City: A Situational Analysis of Strip Clubs, Land Use Conflict, and Occupational Health in Portland, Oregon" (2013). Dissertations and Theses. Paper 1046.

Moore, S. (2007). Alternative Routes to the Sustainable City: Austin, Curitiba and Frankfurt. Lexington Books; Lanham, MD.

Murayama, A. (2007). Civic Movements for Sustainable Urban Regeneration: Downtown Fukaya City, Saitama prefecture. In Sorenson, A. and Funck, C. (eds.) Living Cities in Japan. New York, NY: Routledge.

Murayama, A. \& Sharifi, A. (2011). Low-Carbon Strategy and Community Development in Nagoya, Japan: Case of Nishiki 2 District, a Fabric Warehouse District in 
Transition. Conference Proceedings, EcoDistricts Summit, October 27, 2011, Portland, Oregon.

Navarro, V. and Shi, L. (2001). The political context of social inequalities and health. Social Science and Medicine, 52(3), 481-491.

Norton, B. and Hannon, B. (2004). Democracy and sense of place values in environmental policy. In Norton, B. (Ed.) Searching for Sustainability: Interdisciplinary Essays in the Philosophy of Conservation Biology. Cambridge University Press: Cambridge, U.K.

Ompad, D. C., Galea, S., Caiaffa, W. T., \& Vlahov, D. (2007). Social determinants of the health of urban populations: methodologic considerations. Journal of Urban Health: Bulletin of the New York Academy of Medicine, 84, 3, 42-53.

Papayanis, M. (2000). Sex and the revanchist city: zoning out pornography in New York. Environment and Planning D: Society and Space, 18, 341-54.

Polese, M. and Stren, R. (2000). Social sustainability of cities: Diversity and the management of change. University of Toronto Press: Toronto, Canada.

Popper, F. J. (1981). Siting LULU's. Planning, 47(4), 12-15.

Roemer, J. and Van der Straeten, K. (2006). The political economy of xenophobia and distribution: The case of Denmark. Scand. J. or Economics, 108(2), 251-277. 
Saha, D., \& Paterson, R. G. (2008). Local Government Efforts to Promote the "Three Es" of Sustainable Development. Journal of Planning Education and Research, 28(1), 21 -37. doi:10.1177/0739456X08321803.

Seltzer, E., Smith, T., Cortright, J., Bassett, E., and Shandas, V. (2010). Making EcoDistricts: Concepts and Methods for Advancing Sustainability in Neighborhoods. Report for the Bullitt Foundation, 1-122.

Sorensen, A. (2002). The Making of Urban Japan: Cities and planning from Edo to the twenty-first century. Nissan Institute/Routledge Japanese Studies Series: New York, NY.

Taket, A., Crisp, B., Graham, M., Hanna, L., and Goldingay, S. (2014). Scoping social inclusion practice. In Taket, A., Crisp, B., Graham, M., Hanna, L., Goldingay, S., and Wilson, L. (Eds). Practising Social Inclusion. Routledge: London \& New York.

Vallance, S., Perkins, H. C., \& Dixon, J. E. (2011). What is social sustainability? A clarification of concepts. Geoforum, 42(3), 342-348.

Watanabe, S.J. (2007). Toshi Keikaku vs. Machizukuri : Emerging paradigm of civil society in Japan, 1950-1980. In Sorenson, A. and Funck, C. (2007). Living Cities in Japan : Citizens' Movements, Machizukuri and Local Environments. Nissan Institute/Routledge Japanese Studies Series : New York, NY.

Wilkinson, R. (1996). Unhealthy Societies. The Afflictions of Inequality. Routledge ; 
London.

Williams, D. and Collins, C. (2001). Racial Residential Segregation: A Fundamental Cause of Racial Disparities in Health. Public Health Reports, Sept-Oct, Vol. 116, p. 404416.

World Health Organization. (2008). Commission on Social Determinants of Health. CSDH Final Report: Closing the Gap in a Generation: Health Equity Through Action on the Social Determinants of Health. Geneva, Switzerland: World Health Organization.

WHO (2007). A Conceptual Framework for Action on the Social Determinants of Health. Commission on Social Determinants of Health. Retrieved at: http://www.who.int/social determinants/resources/csdh framework action 0 $\underline{5 \text { 07.pdf?ua }=1}$

Yin, R. (2014). Case Study Research: Design and Methods. Fifth edition. Thousand Oaks, CA: Sage Publications, Inc.

Zeemering, E. S. (2009). What Does Sustainability Mean to City Officials? Urban Affairs Review, 45(2), 247 -273. doi:10.1177/1078087409337297. 
Appendix - Interview Results and SDH Template Analysis Summary

\begin{tabular}{|c|c|c|c|c|c|c|c|}
\hline \multicolumn{2}{|c|}{$\begin{array}{l}\text { Interview Results and } \\
\text { SDH Template Analysis } \\
\text { Summary }\end{array}$} & \multicolumn{2}{|l|}{$\begin{array}{l}\text { Living Cully, } \\
\text { Portland }\end{array}$} & \multicolumn{2}{|l|}{$\begin{array}{l}\text { Sankt Kjelds, } \\
\text { Copenhagen }\end{array}$} & \multicolumn{2}{|l|}{$\begin{array}{l}\text { Chojamachi, } \\
\text { Nagoya }\end{array}$} \\
\hline \multirow{8}{*}{ 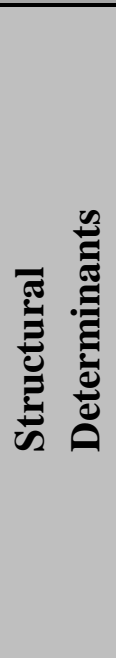 } & Income, wealth & Home ownership & 4 & & 0 & $\begin{array}{l}\text { Increasing income } \\
\text { for business-owners }\end{array}$ & 4 \\
\hline & $\begin{array}{l}\text { Education, literacy, } \\
\text { skills }\end{array}$ & $\begin{array}{l}\text { Job training; } \\
\text { capacity building }\end{array}$ & 4 & $\begin{array}{l}\text { Integration of school; } \\
\text { teaching youth skills }\end{array}$ & 4 & & 0 \\
\hline & $\begin{array}{l}\text { Occupation: } \\
\text { Employment, } \\
\text { unemployment, } \\
\text { working conditions }\end{array}$ & $\begin{array}{l}\text { Connecting green } \\
\text { jobs to low- } \\
\text { income workers }\end{array}$ & 4 & $\begin{array}{l}\text { Creating workspaces for } \\
\text { young people }\end{array}$ & 4 & $\begin{array}{l}\text { Creating } \\
\text { employment } \\
\text { opportunities for } \\
\text { young people }\end{array}$ & 4 \\
\hline & $\begin{array}{l}\text { Social class, status, } \\
\text { poverty }\end{array}$ & Anti-poverty & 4 & $\begin{array}{l}\text { Integration of social } \\
\text { classes }\end{array}$ & 4 & $\begin{array}{l}\text { Advocating for } \\
\text { people in need }\end{array}$ & 3 \\
\hline & Gender, human rights & $\begin{array}{l}\text { Environmental } \\
\text { justice }\end{array}$ & 4 & $\begin{array}{l}\text { Keeping young girls } \\
\text { active }\end{array}$ & 0 & & 2 \\
\hline & Race/ ethnicity & $\begin{array}{l}\text { People of color in } \\
\text { community } \\
\text { representation }\end{array}$ & 4 & $\begin{array}{l}\text { Integration of } \\
\text { immigrants in sports } \\
\text { clubs and local school }\end{array}$ & 4 & & 0 \\
\hline & Equity, social justice & $\begin{array}{l}\text { Environmental } \\
\text { justice; equity }\end{array}$ & 4 & $\begin{array}{l}\text { Equitable living } \\
\text { conditions }\end{array}$ & 4 & Social equity & 3 \\
\hline & \multicolumn{2}{|c|}{ Structural Determinants Total } & 28 & & 20 & & 16 \\
\hline \multirow{10}{*}{ 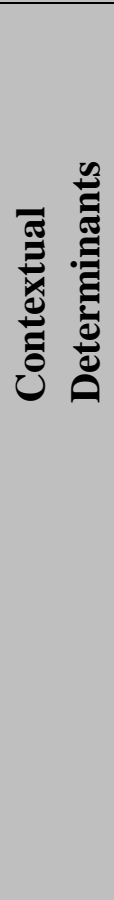 } & $\begin{array}{l}\text { Social Environments: } \\
\text { Social mixing, networks, } \\
\text { cohesion, social capital }\end{array}$ & $\begin{array}{l}\text { Social cohesion; } \\
\text { social gathering } \\
\text { spaces }\end{array}$ & 3 & $\begin{array}{l}\text { Creating opportunities } \\
\text { for social interaction, } \\
\text { gathering spaces }\end{array}$ & 4 & $\begin{array}{l}\text { Creating kaisho } \\
\text { (meeting places); } \\
\text { social inclusion }\end{array}$ & 4 \\
\hline & $\begin{array}{l}\text { Physical Environments: } \\
\text { Housing, safety, } \\
\text { environmental health }\end{array}$ & $\begin{array}{l}\text { Increasing } \\
\text { greenspace; } \\
\text { sidewalks }\end{array}$ & 4 & Upgrading housing units & 4 & $\begin{array}{l}\text { Development of an } \\
\text { intergenerational } \\
\text { housing complex }\end{array}$ & 4 \\
\hline & $\begin{array}{l}\text { Personal health } \\
\text { practices, coping skills }\end{array}$ & $\begin{array}{l}\text { Promote physical } \\
\text { activity }\end{array}$ & 4 & $\begin{array}{l}\text { Routes for physical } \\
\text { activity }\end{array}$ & 4 & $\begin{array}{l}\text { Encouraging } \\
\text { walking }\end{array}$ & 4 \\
\hline & $\begin{array}{l}\text { Healthy child } \\
\text { development }\end{array}$ & $\begin{array}{l}\text { Parks; safe } \\
\text { walking routes }\end{array}$ & 4 & $\begin{array}{l}\text { Childcare; } \\
\text { intergenerational living }\end{array}$ & 4 & $\begin{array}{l}\text { Better conditions } \\
\text { for raising children }\end{array}$ & 4 \\
\hline & $\begin{array}{l}\text { Health system, service } \\
\text { delivery }\end{array}$ & & 0 & & 0 & $\begin{array}{l}\text { Social service needs } \\
\text { of older adults }\end{array}$ & 4 \\
\hline & $\begin{array}{l}\text { Culture, identity, sense } \\
\text { of place }\end{array}$ & $\begin{array}{l}\text { Native } \\
\text { epistemologies; } \\
\text { tribal gathering } \\
\text { garden }\end{array}$ & 4 & $\begin{array}{l}\text { Creating an identity; } \\
\text { sense of belonging; } \\
\text { Culture House }\end{array}$ & 4 & $\begin{array}{l}\text { Karuta; machizukuri } \\
\text { practices to harness } \\
\text { cultural meanings; } \\
\text { community festivals }\end{array}$ & 4 \\
\hline & $\begin{array}{l}\text { Demo. change: Aging, } \\
\text { migration, } \\
\text { gentrification, } \\
\text { displacement }\end{array}$ & $\begin{array}{l}\text { Anti- } \\
\text { displacement }\end{array}$ & 4 & $\begin{array}{l}\text { Supporting needs of } \\
\text { older adults with } \\
\text { mobility constraints }\end{array}$ & 4 & $\begin{array}{l}\text { Securing living } \\
\text { environments for } \\
\text { all generations }\end{array}$ & 4 \\
\hline & $\begin{array}{l}\text { Empowerment, } \\
\text { participation, access }\end{array}$ & $\begin{array}{l}\text { Empowerment, } \\
\text { equity of access }\end{array}$ & 4 & $\begin{array}{l}\text { Open participation in } \\
\text { planning committees }\end{array}$ & 4 & $\begin{array}{l}\text { Machizukuri civic } \\
\text { engagement }\end{array}$ & 4 \\
\hline & $\begin{array}{l}\text { Well-being, happiness, } \\
\text { quality of life }\end{array}$ & $\begin{array}{l}\text { Well-being, } \\
\text { quality of life }\end{array}$ & 3 & $\begin{array}{l}\text { Culture House; quality } \\
\text { of life }\end{array}$ & 4 & Quality of life & 3 \\
\hline & \multicolumn{2}{|c|}{ Contextual Determinants Total } & 30 & & 32 & & 35 \\
\hline & \multicolumn{3}{|c|}{ Key for template analysis ratings: } & \multirow{6}{*}{\multicolumn{4}{|c|}{$\begin{array}{l}\text { The left column for each neighborhood indicates } \\
\text { conceptualizations discussed during interviews, while numbers } \\
\text { in the right column indicate ratings assigned during template } \\
\text { analysis. }\end{array}$}} \\
\hline & \multicolumn{2}{|c|}{ Not Mentioned } & 0 & & & & \\
\hline & \multicolumn{2}{|l|}{ Mentioned x1 } & 1 & & & & \\
\hline & \multicolumn{2}{|c|}{ Mentioned and Importance Stressed } & 2 & & & & \\
\hline & \multicolumn{2}{|l|}{ Actionable Ideas Discussed } & 3 & & & & \\
\hline & \multicolumn{2}{|l|}{ Plan Outlined } & 4 & & & & \\
\hline
\end{tabular}

